\title{
Post-retrieval disruption of a cocaine conditioned place preference by systemic and intrabasolateral amygdala $\boldsymbol{\beta}_{2^{-}}$and $\boldsymbol{\alpha}_{1}$-adrenergic antagonists
}

\author{
Rick E. Bernardi, ${ }^{1,4}$ Andrey E. Ryabinin, ${ }^{1}$ S. Paul Berger, ${ }^{1,2,3}$ and K. Matthew Lattal ${ }^{1}$ \\ ${ }^{1}$ Department of Behavioral Neuroscience, Oregon Health and Science University, Portland, Oregon 97239, USA; ${ }^{2}$ Department of \\ Psychiatry, Oregon Health and Science University, Portland, Oregon 97239, USA; ${ }^{3}$ Department of Psychiatry, Portland Veterans' \\ Affairs Medical Center, Portland, Oregon 97239, USA
}

\begin{abstract}
Previous work has demonstrated post-retrieval impairment in associative learning paradigms, including those mediated by drugs of abuse, using nonspecific $\beta$-adrenergic receptor ( $\beta$-AR) antagonists. Remarkably little is known about the role of the specific $\beta$-AR subtypes, or other adrenergic receptors, in these effects. The current study examined the effects of $\beta_{1}$ and $\beta_{2}$, as well as $\alpha_{1}$-adrenergic receptor antagonism following retrieval of a cocaine conditioned place preference (CPP). We found that rats administered the $\beta_{2}$ antagonist ICl 118,551 (8 $\mathrm{mg} / \mathrm{kg}$ intraperitoneal [IP]) or the $\alpha_{1}$ antagonist prazosin (1 mg/ kg IP) following a drug-free test for CPP showed attenuated preference during a subsequent test, while the $\beta_{1}$ antagonist betaxolol ( 5 or $10 \mathrm{mg} / \mathrm{kg}$ IP) and a lower dose of prazosin ( $0.3 \mathrm{mg} / \mathrm{kg} \mathrm{IP}$ ) had no effect. Furthermore, posttest microinfusion of $\mathrm{ICl} 118,551(6 \mathrm{nmol} / \mathrm{side})$ or prazosin $(0.5 \mathrm{nmol} / \mathrm{side})$ into the basolateral amygdala (BLA) also impaired a subsequent preference. Systemic or intra-BLA ICI 118,551 or prazosin administered to rats in their home cages, in the absence of a preference test, had no effect on CPP 24 h later. ICI 118,551 also attenuated the FOS response in the BLA induced by the CPP test. These results are the first to demonstrate a role for $\alpha_{1^{-}}$and $\beta_{2^{-}}$specific adrenergic mechanisms in post-retrieval memory processes. These systemic and site-specific injections, as well as the FOS immunohistochemical analyses, implicate the importance of specific noradrenergic signaling mechanisms within the BLA in post-retrieval plasticity.
\end{abstract}

Substantial evidence indicates that information acquired during a learning event is initially plastic, at which time memory retention can be disrupted, but is strengthened by a time-dependent consolidation process (McGaugh 2000). Recent work has focused on retrieval-induced plasticity, a process by which changes in the retention of previously acquired information are possible. The notion of reconsolidation, one theoretical mechanism by which such changes may occur, suggests that a retrieved memory enters a labile state and is vulnerable to disruption (Sara 2000; Nader 2003). Although the theoretical mechanisms underlying reconsolidation remain unclear, the behavioral effects have been demonstrated across many different learning paradigms using a variety of pharmacological manipulations (for review, see Tronson and Taylor 2007; Diergaarde et al. 2008). Studies with aversive and appetitive preparations, including drug reward-mediated learning, have demonstrated that the noradrenergic system is important for these post-retrieval memory processes (Przybyslawski et al. 1999; Debiec and Ledoux 2004; Bernardi et al. 2006; Diergaarde et al. 2006; Robinson and Franklin 2007; Abrari et al. 2008; FricksGleason and Marshall 2008; Milton et al. 2008). For example, using an animal model of cocaine-conditioned behaviors, Bernardi et al. (2006) demonstrated that systemic post-retrieval administration of propranolol impaired a subsequent conditioned place preference (CPP), suggesting that $\beta$-adrenergic receptors ( $\beta$-ARs) play an important role in processes occurring following drug memory retrieval.

However, most of what is known about the noradrenergic system in the memory processes that follow cued reminder trials

\footnotetext{
${ }^{4}$ Corresponding author.
}

E-mail rick.bernardi@zi-mannheim.de; fax (503) 494-6877.

Article is online at http://www.learnmem.org/cgi/doi/10.1101//m.1648509. comes from studies that use nonspecific $\beta$-AR antagonists, such as propranolol. As a consequence, several issues regarding ARs and post-retrieval memory processes remain unresolved. First, because propranolol has affinity for both $\beta_{1^{-}}$and $\beta_{2}$-AR subtypes, it is unclear which subtype mediates these effects. To date, no studies have examined reconsolidation-like impairments using subtypespecific $\beta$-AR antagonists, which is important because more specific medications may be equally efficacious with less adverse effects. Second, no studies to date have examined $\alpha$-ARs regarding a potential role in reconsolidation-like effects. $\alpha$-ARs_-specifically $\alpha_{1}$-ARs - have a demonstrated role in memory consolidation (Ferry et al. 1999a,b) and may also mediate post-retrieval processes. Third, although the BLA has had a demonstrated role in reconsolidation-like effects in numerous studies, the behavioral conditions during retrieval of drug-associated memories leading to gene expression within the basolateral amygdala (BLA) have not clearly been defined. Specifically, in the CPP paradigm used here, it is unclear whether exposure to a cocaine cue alone will induce gene expression or whether a preference for the drug-associated environment needs to be expressed for BLA involvement (Franklin and Druhan 2000; Miller and Marshall 2005).

Understanding the role of specific adrenergic receptors in mediating post-retrieval memory processes is particularly important in drug-induced CPP. In humans, drug-associated stimuli can facilitate drug use (Gawin 1991; See 2005) or precipitate relapse following abstinence (O'Brien et al. 1992). Thus, pharmacotherapies targeting these memory processes would benefit from a clearer understanding of the specific receptors that mediate behavioral effects (Taylor et al. 2009).

Here, we first examined the effects of systemic post-test $\beta_{1^{-}}$, $\beta_{2^{-}}$, and $\alpha_{1}$-AR antagonism on cocaine CPP. We then focused on the BLA due to its involvement in reconsolidation-like effects in 
drug learning paradigms (e.g., Lee et al. 2005), employing microinfusions of AR antagonists and measuring FOS immunoreactivity (FOS-IR) to examine the BLA as a potential site of AR-mediated impairments.

\section{Results}

\section{Experiment 1A: Post-retrieval betaxolol administration} failed to alter a subsequent $C P P$

Rats in each group showed a CPP during test 1 , prior to betaxolol or vehicle (VEH) administration. Figure $1 \mathrm{~A}$ shows the mean (+ SEM) time spent on the GRID floor during test 1 for groups BET-0, BET-5, and BET-10. A two-way ANOVA (betaxolol dose $\times$ conditioning subgroup) revealed a significant main effect of conditioning subgroup $\left(F_{(1,66)}=90.6, P<0.001\right)$, indicating reliable preference across drug treatments for the cocaine-paired floor, but no interaction or main effect of betaxolol $(F s<1)$. Further analysis with Student's $t$-test comparing time spent on the GRID floor for the GRID+ and GRID- subgroups within each drug treatment confirmed that groups BET-0 $\left(t_{(22)}=6.5, P<0.001\right)$, BET-5 $\left(t_{(22)}=6.7, P<0.001\right)$, and BET-10 $\left(t_{(22)}=3.9, P<0.001\right.$; Bonferroni-corrected $\alpha / 3=0.017$ ), prior to their respective treatments, all showed significant cocaine-induced CPP.

Rats that received betaxolol following test 1 continued to show a CPP during test 2 . Figure $1 B$ shows the mean (+ SEM) time spent on the GRID floor during test 2 for groups BET-0, BET-5, and BET-10. A two-way ANOVA (betaxolol dose $\times$ conditioning subgroup) revealed a significant main effect of conditioning subgroup $\left(F_{(1,66)}=35.7, P<0.001\right)$, again indicating reliable preference for the cocaine-paired floor, but no significant interaction or main effect of betaxolol $(F s<1)$. Student's $t$-test comparing time spent on the GRID floor for the GRID+ and GRID- subgroups within each drug treatment revealed that groups BET-0 $\left(t_{(22)}=3.0, P<\right.$ $0.01)$, BET-5 $\left(t_{(22)}=3.7, P<0.005\right)$, and BET-10 $\left(t_{(22)}=3.7, P<0.005\right.$ [Bonferroni-corrected $\alpha / 3=0.017$ ]) again all showed significant cocaine-induced CPP during test 2 . Thus, the $\beta_{1}$-adrenergic antagonist betaxolol failed to attenuate a CPP for cocaine when administered following test 1 .
A

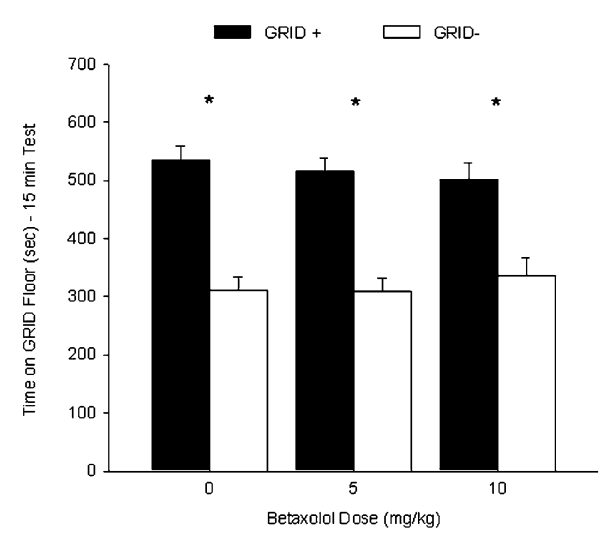

B.

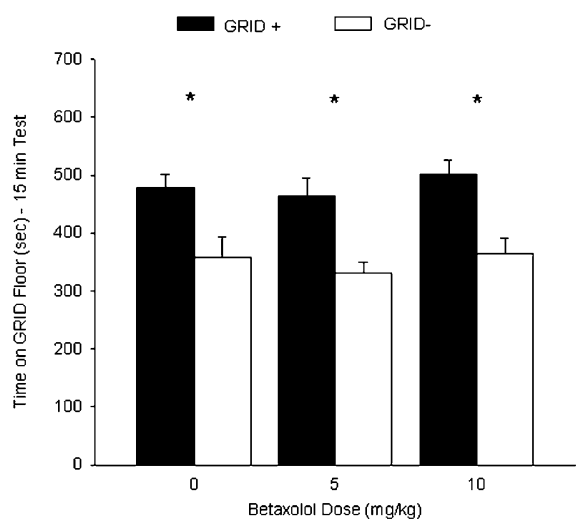

Figure 1. Post-retrieval administration of betaxolol had no effect on a subsequent cocaine-induced conditioned place preference (CPP). (A) Cocaine induced a CPP for the cocaine-paired floor during test 1. Data represent mean (+ SEM) time spent on the GRID floor for the GRID+ and GRID- subgroups during the 15-min drug-free test. All groups showed a significant preference for the cocaine-paired floor. (B) Post-retrieval betaxolol following test 1 did not affect a cocaine-induced CPP during test 2. Data represent mean (+ SEM) time spent on the GRID floor for the GRID+ and GRID- subgroups during the first $15 \mathrm{~min}$ of a 25 -min drug-free test. Rats treated with betaxolol following test 1 continued to show a significant preference for the cocaine-paired floor during test 2 . ${ }^{\star} P<0.017$ (Bonferronicorrected $\alpha / 3)$.
A one-way ANOVA revealed that activity during test 2 did not differ significantly between the three groups (BET-0 $=1341 \pm 49$, BET-5 $=1477 \pm 43$, BET- $\left.10=1391 \pm 54 ; F_{(2,69)}=2.0, P=0.14\right)$.

\section{Experiment 1B: Post-retrieval ICI 118,551 administration attenuated a subsequent CPP}

Rats in each group showed a CPP during test 1 , prior to ICI 118,551 or VEH administration. Figure $2 \mathrm{~A}$ shows the mean (+ SEM) time sent on the GRID floor during test 1 for groups ICI-0 and ICI-8. A two-way ANOVA (ICI 118,551 dose $\times$ conditioning subgroup) revealed a significant main effect of conditioning subgroup $\left(F_{(1,44)}=46.3, P<0.001\right)$, indicating reliable preference across drug treatments for the cocaine-paired floor, but no significant interaction or main effect of ICI 118,551 ( Fs < 1). Student's $t$-test comparing time spent on the GRID floor for the GRID+ and GRID - subgroups within each drug treatment confirmed that groups ICI-0 $\left(t_{(22)}=4.3, P<0.001\right)$ and ICI-8 $\left(t_{(22)}=5.4, P<0.001\right.$ [Bonferroni-corrected $\alpha / 2=0.025]$ ) showed significant cocaineinduced CPP prior to their respective treatments.

Rats that received VEH following test 1 continued to show a CPP during test 2, while ICI 118,551-treated rats failed to show a significant place preference during test 2 . Figure $2 \mathrm{~B}$ shows the mean (+ SEM) time spent on the GRID floor during test 2 for groups ICI-0 and ICI-8. A two-way ANOVA (ICI 118,551 dose $\times$ conditioning subgroup) revealed a significant main effect of conditioning subgroup $\left(F_{(1,44)}=13.7, P<0.001\right)$, indicating preference for the cocaine-paired floor, but no significant interaction $\left(F_{(1,44)}=2.2, P=0.14\right)$ or main effect of ICI 118,551 $(F<1)$. However, Student's $t$-test comparing time spent on the GRID floor for the GRID+ and GRID- subgroups within each drug treatment revealed that while group ICI-0 $\left(t_{(22)}=3.9, P<0.001\right.$ [Bonferroni-corrected $\alpha / 2=0.025$ ]) continued to show a significant place preference for the cocaine-paired floor, group ICI-8 $t_{(22)}=1.5, P>0.15$ [Bonferroni-corrected $\left.\alpha / 2=0.025\right]$ ) no longer showed a significant preference during test 2 . These results suggest cocaine when administered following test 1 .

Activity during test 2 did not differ between the two groups ICI-0 (1391 \pm 53$)$ and IC1-8 (1368 \pm 57$)$, as revealed by a one-way ANOVA $(F<1)$. Thus, the difference in preference between the two groups was not due to a residual or conditioned locomotor effect of the drug.

\section{Experiment 1C: ICI 118,551}

administration had no effect on CPP in the absence of retrieval Rats receiving ICI 118,551 or $\mathrm{VEH}$ in their home cages, in the absence of test 1 , showed no difference in CPP during test 2 . Figure 3 shows the mean (+ SEM) time spent on the GRID floor during test 2 for groups ICI-0-NR and ICI-8-NR. A two-way ANOVA (ICI dose $\times$ conditioning subgroup) revealed a significant main effect of conditioning subgroup $\left(F_{(1,44)}=\right.$ $156.2, P<0.001)$, suggesting reliable preference for the cocaine-paired floor, but no significant interaction or main effect of ICI 118,551 ( $F \mathrm{~s}<1)$. Student's t-test comparing time spent on the GRID floor for the GRID+ and GRID - subgroups confirmed that both the ICI-0-NR $\left(t_{(22)}=9.1\right.$, $P<0.001)$ and ICI-8-NR $\left(t_{(22)}=8.5, P<\right.$ 0.001 [Bonferroni-corrected $\alpha / 2=0.025$ ]) 
A.

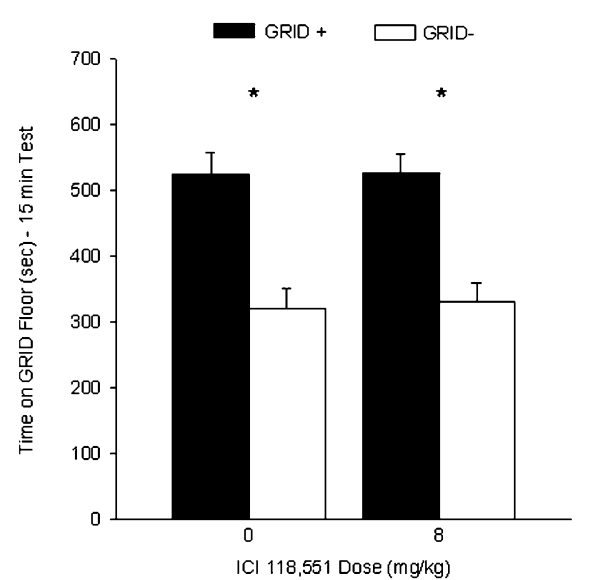

B.

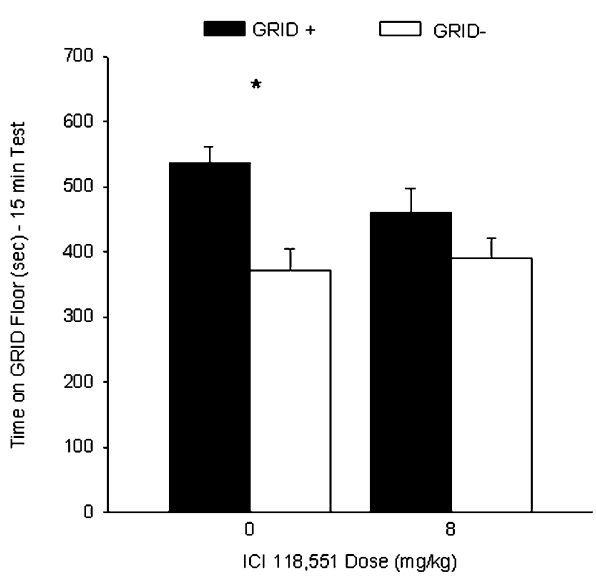

Figure 2. Post-retrieval administration of $\mathrm{ICI} 118,551$ attenuated a subsequent cocaine-induced conditioned place preference (CPP). ( $A$ ) Cocaine induced a CPP for the cocaine-paired floor during test 1. Data represent mean (+ SEM) time spent on the GRID floor for the GRID+ and GRID- subgroups during the 15-min drug-free test. Both groups showed a significant preference for the cocaine-paired floor. (B) Post-retrieval ICI 118,551 following test 1 attenuated a cocaine-induced CPP during test 2. Data represent mean (+ SEM) time spent on the GRID floor for the GRID+ and GRID- subgroups during the first 15 min of a 25-min drug-free test. Rats treated with ICI 118,551 following test 1 showed no significant preference for the cocaine-paired floor during test 2, while vehicle-treated rats continued to show a significant CPP. ${ }^{*} P<0.025$ (Bonferroni-corrected $\alpha / 2$ ).

groups showed significant cocaine-induced CPP, suggesting that the effect seen in the ICI-8 group in experiment 2 was specific to exposure to the testing environment.

A one-way ANOVA revealed no activity difference between the ICI-0-NR (1587 \pm 43$)$ and ICI-8-NR $(1604 \pm 45)$ groups $(F<1)$, suggesting no residual locomotor effect of the drug.

\section{Experiment ID: Post-retrieval prazosin administration attenuated a subsequent CPP}

Rats in each drug treatment group showed a CPP during test 1 , prior to prazosin or VEH administration. Figure $4 \mathrm{~A}$ shows the mean (+ SEM) time spent on the GRID floor during test 1 for all groups. A two-way ANOVA (prazosin dose $\times$ conditioning subgroup) revealed a significant main effect of conditioning subgroup $\left(F_{(1,90)}=73.8, P<0.001\right)$, indicating reliable preference across drug treatments for the cocaine-paired floor, but no interaction $\left(F_{(2,90)}=\right.$ $2.4, P=0.10)$ or main effect of prazosin $(F<1)$. Student's $t$-test comparing time spent on the GRID floor for the GRID+ and GRID - subgroups within each drug treatment confirmed that groups PRAZ-0 $\left(t_{(30)}=6.8, P<0.001\right)$, PRAZ-0.3 $\left(t_{(30)}=5.2, P<\right.$ $0.001)$, and PRAZ-1 $\left(t_{(30)}=3.2, P<0.005\right.$ [Bonferroni-corrected $\alpha / 3=0.017]$ ) all showed significant cocaine-induced CPP prior to their respective treatments.

Rats that received $\mathrm{VEH}$ and $0.3 \mathrm{mg} / \mathrm{kg}$ prazosin following test 1 continued to show a CPP during test 2 , while $1 \mathrm{mg} / \mathrm{kg}$ prazosintreated rats failed to show a significant place preference during test 2. Figure $4 \mathrm{~B}$ shows the mean (+ SEM) time spent on the GRID floor during test 2 for all groups. A two-way ANOVA (prazosin dose $\times$ conditioning subgroup) revealed a significant interaction $\left(F_{(2,90)}=\right.$ 5.2, $P<0.01)$ and a significant main effect of conditioning subgroup $\left(F_{(1,90)}=30.5, P<0.001\right)$, but no main effect of prazosin dose $(F<1)$. Follow-up two-way ANOVAs for each pair of prazosin doses revealed significant interactions between the PRAZ-0 and PRAZ-1 groups $\left(F_{(1,60)}=4.2, P<0.05\right)$ and the PRAZ-0.3 and PRAZ-1 groups $\left(F_{(1,60)}=10.5, P<0.005\right)$, and significant main effects of conditioning subgroup $\left(F \mathrm{~s}_{(1,60)}>9.3, P \mathrm{~s}<0.005\right)$ but not prazosin dose $(F \mathrm{~s}<1)$, indicating a difference in preference based on dose.
There was no significant interaction between the PRAZ-0 and PRAZ-0.3 groups $\left(F_{(1,60)}=1.3, P=0.26\right)$ or main effect of prazosin dose $(F<1)$, but a significant effect of conditioning subgroup $\left(F_{(1,60)}=\right.$ $10.5, P<0.005)$, indicating reliable preference. Student's $t$-tests comparing time spent on the GRID floor for the GRID+ and GRID - subgroups within each prazosin dose confirmed that groups PRAZ-0 $\left(t_{(30)}=3.5, P<0.005\right)$ and PRAZ-0.3 $\left(t_{(30)}=\right.$ $5.3, P<0.001)$ continued to show a preference during test 2; the PRAZ-1 group $\left(t_{(30)}=3.2, P=0.47\right)$ no longer showed a preference for the cocaine-paired floor (Bonferroni-corrected $\alpha / 3=0.017$ ). These results suggest that a $1 \mathrm{mg} / \mathrm{kg}$ dose of the $\alpha_{1}$-adrenergic antagonist prazosin attenuated a CPP for cocaine when administered following test 1.

Activity during test 2 did not differ between the three groups (PRAZ-0 = $1427 \pm 41$, PRAZ-0.3 = $1362 \pm 51$, PRAZ$1=1448 \pm 47)$, as revealed by a one-way ANOVA $(F<1)$, suggesting that the difference in preference in the PRAZ-0 group was not due to a residual or conditioned locomotor effect of the drug.

\section{Experiment 1E: Prazosin administration had no effect} on CPP in the absence of retrieval

Groups that received VEH or $1 \mathrm{mg} / \mathrm{kg}$ prazosin in the absence of test 1 showed no difference in CPP during test 2. Figure 5 shows the mean (+ SEM) time spent on the GRID floor during test 2 for groups PRAZ-0-NR and PRAZ-1-NR. A two-way ANOVA (prazosin dose $\times$ conditioning subgroup) revealed a significant main effect of conditioning subgroup $\left(F_{(1,46)}=156.2, P<0.001\right)$ but no interaction or main effect of prazosin $(F s<1)$, suggesting reliable preference for the cocaine-paired floor. Student's $t$-test confirmed that both the PRAZ-0-NR $\left(t_{(22)}=8.4, P<0.001\right)$ and PRAZ-1-NR $\left(t_{(22)}=9.5, P<0.001\right.$ [Bonferroni-corrected $\left.\left.\alpha / 2=0.025\right]\right)$ groups showed significant cocaine-induced CPP, suggesting that the effect

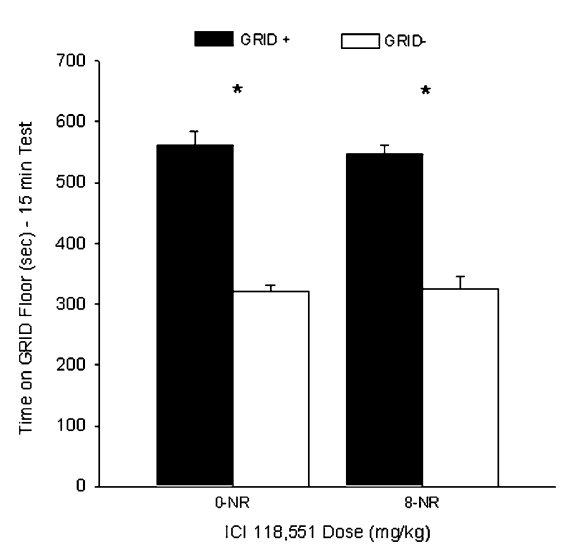

Figure 3. No effect of $\mathrm{ICl} 118,551$ on a cocaine conditioned place preference (CPP) when administered in the absence of re-exposure. Data represent mean (+ SEM) time spent on GRID floor for the GRID+ and GRID - subgroups during the first $15 \mathrm{~min}$ of the 25 -min drug-free test. Groups that received ICI 118,551 or vehicle in the absence of test 1 (NR) both showed a significant cocaine CPP during test 2 . ${ }^{*} P<0.025$ (Bonferroni-corrected $\alpha / 2$ ). NR indicates no re-exposure. 
A

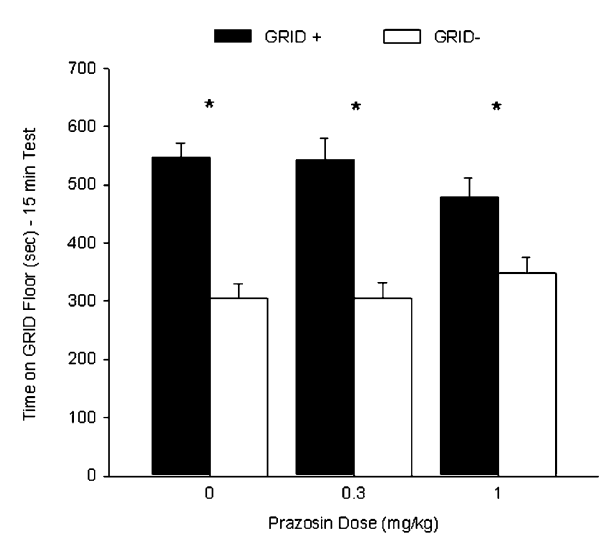

B.

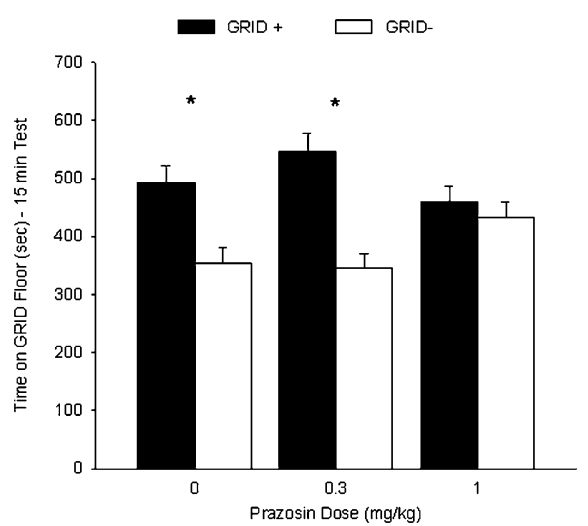

Figure 4. Post-retrieval administration of the highest dose of prazosin attenuated a subsequent cocaine-induced conditioned place preference (CPP). ( $A$ ) Cocaine induced a CPP for the cocaine-paired floor during test 1. Data represent mean (+ SEM) time spent on GRID floor for the GRID+ and GRIDsubgroups during the 15-min drug-free test. Prior to prazosin administration, all groups showed a significant preference for the cocaine-paired floor. (B) Post-retrieval prazosin attenuated a cocaineinduced CPP. Data represent mean (+ SEM) time spent on GRID floor for the GRID+ and GRIDsubgroups during the first $15 \mathrm{~min}$ of the 25 -min drug-free test. Rats treated with $1 \mathrm{mg} / \mathrm{kg}$ prazosin following test 1 showed no preference for the cocaine-paired floor during test 2, while rats administered vehicle or $0.3 \mathrm{mg} / \mathrm{kg}$ prazosin continued to express a significant preference for the cocaine-paired floor. $* P<0.017$ (Bonferroni-corrected $\alpha / 3$ ).

seen in the PRAZ-1 group in experiment 1 was specific to exposure to the testing environment.

A one-way ANOVA revealed no difference between the PRAZ0-NR (1591 \pm 55$)$ and PRAZ-1-NR $(1601 \pm 56)$ groups $(F<1)$, suggesting no residual locomotor effect of the drug.

\section{Experiment 2: Prazosin and ICI 118,551 had no conditioned aversive effect}

Prazosin and ICI 118,551, when administered following CS exposure, failed to alter the neutral preference for the distinct floor cues. Figure 6 shows the mean (+ SEM) time spent on the GRID floor during a preference test for groups VEH, PRAZ-1, and BET-8. Separate two-way ANOVAs (drug treatment $\times$ conditioning subgroup) between the PRAZ-1 or BET-8 groups and the VEH group revealed no significant interactions $\left(F \mathrm{~s}_{(1,28)}>1.7, P \mathrm{~s}>0.20\right)$ or main effects $(F s<1)$. Therefore, at the doses used here, these drugs are not aversive, suggesting the reconditioning of an aversion to the preferred, cocaine-paired cue following the initial tests of preference is not a likely explanation for the test $2 \mathrm{im}$ pairments in CPP seen in experiments $1 \mathrm{~B}$ and $1 \mathrm{D}$.

\section{Experiment 3A: Post-retrieval intra-BLA prazosin and $\mathrm{ICl} 118,551$ administration attenuated a subsequent CPP} Rats in each drug treatment group (VEH, PRAZ, and ICI) showed a CPP during test 1, prior to drug treatment. Figure 7A shows the mean (+ SEM) time spent on the GRID floor during test 1 for all groups. Separate two-way ANOVAs (post-test treatment $\times$ conditioning subgroup) were conducted between the PRAZ or ICI groups and the VEH group. Between the PRAZ and VEH groups, a two-way ANOVA revealed a significant main effect of conditioning subgroup $\left(F_{(1,29)}=83.1, P<0.001\right)$, indicating reliable preference across drug treatments for the cocaine-paired floor, but no interaction $\left(F_{(1,29)}=2.4, P=0.13\right)$ or main effect of prazosin $\left(F_{(1,29)}=3.9, P=0.06\right)$. Between the ICI and VEH groups, a two-way ANOVA revealed a significant main effect of conditioning subgroup $\left(F_{(1,28)}=44.8, P<0.001\right)$, again indicating reliable preference across drug treatments for the cocaine-paired floor, but no in- teraction $(F<1)$ or main effect of ICI $118,551\left(F_{(1,28)}=1.2, P=0.28\right)$. Follow-up Student's $t$-tests comparing time spent on the GRID floor for the GRID+ and GRIDsubgroups within each drug treatment confirmed that the VEH $\left(t_{(14)}=4.9, P<\right.$ 0.001), PRAZ $\left(t_{(15)}=8.3, P<0.001\right)$, and ICI groups $\left(t_{(14)}=4.6, P<0.001\right.$ [Bonferroni-corrected $\alpha / 3=0.017]$ ) all showed a significant preference during test 1 , prior to their respective treatments.

Rats that received $\mathrm{VEH}$ following test 1 continued to show a CPP during test 2, while prazosin-treated and ICI 118,551-treated rats failed to show a significant place preference during test 2 . Figure $7 \mathrm{~B}$ shows the mean (+ SEM) time spent on the GRID floor during test 2 for all groups. Separate two-way ANOVAs (post-test treatment $\times$ conditioning subgroup) were conducted between the PRAZ or ICI groups and the VEH group. Between the PRAZ and VEH groups, a two-way ANOVA revealed a significant main effect of conditioning subgroup $\left(F_{(1,29)}=9.8, P<0.005\right)$, indicating reliable preference across drug treatments for the cocaine-paired floor, but no interaction or main effect of prazosin $(F s<1)$. Between the ICI and VEH groups, a two-way ANOVA revealed a significant main effect of conditioning subgroup $\left(F_{(1,28)}=7.3, P<0.05\right)$, again indicating reliable preference across drug treatments for the cocaine-paired floor, but no interaction $\left(F_{(1,28)}=2.5, P=0.13\right)$ or main effect of ICI $118,551(F<1)$. However, follow-up Student's $t$-tests comparing time spent on the GRID floor for the GRID+ and GRID- subgroups within each drug treatment revealed that while the VEH group $\left(t_{(14)}=2.9, P<0.017\right)$ continued to show a preference during test 2 , groups PRAZ $\left(t_{(15)}=1.5, P=0.15\right)$ and ICI $\left(t_{(14)}=0.8, P=0.42\right)$ no longer showed a significant preference for the cocaine-paired floor (Bonferroni-corrected $\alpha / 3=0.017$ ). Thus, intra-BLA microinfusion of either prazosin or ICI 118,551 immediately after test 1 attenuated a preference during test 2 . These findings are consistent with systemic findings reported earlier (Figs. 2 and 4).

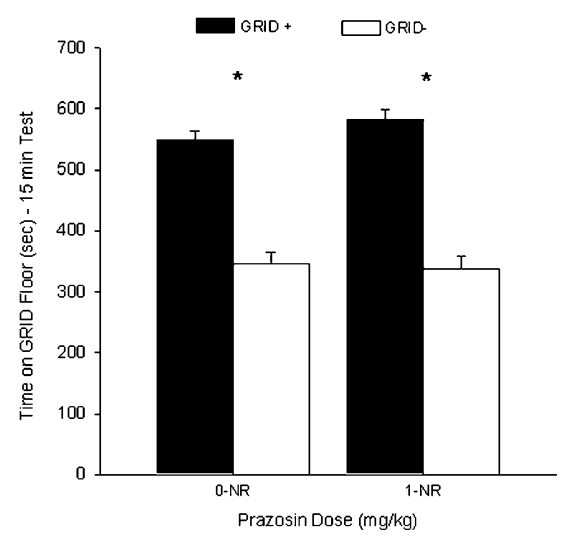

Figure 5. No effect of prazosin on a cocaine conditioned place preference (CPP) when administered in the absence of re-exposure. Data represent mean (+ SEM) time spent on GRID floor for the GRID+ and GRID - subgroups during the first $15 \mathrm{~min}$ of the 25 -min drug-free test. Groups that received vehicle or $1 \mathrm{mg} / \mathrm{kg}$ prazosin in the absence of test 1 (NR) both showed a significant cocaine CPP during test $2 .{ }^{*} P<0.025$ (Bonferroni-corrected $\alpha / 2$ ). NR indicates no re-exposure. 


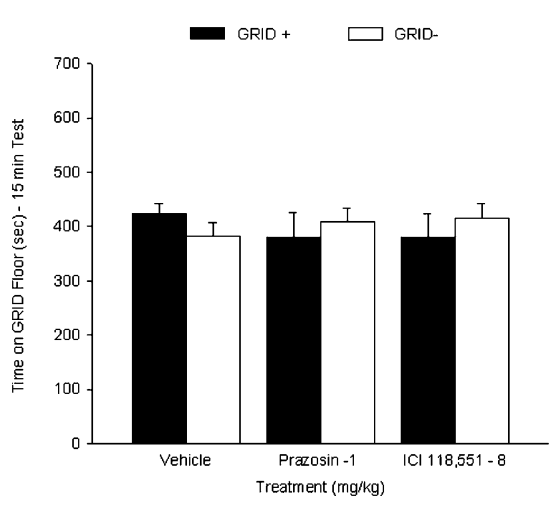

Figure 6. No effect of prazosin or ICI 118,551 when administered after one of two distinct CS exposures. Data represent mean (+ SEM) time spent on GRID floor for the GRID+ and GRID - subgroups during the first $15 \mathrm{~min}$ of the 25 -min test. Groups that received vehicle, $1 \mathrm{mg} / \mathrm{kg}$

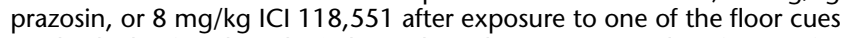
(and vehicle after the other) showed no change in neutral preference for the two cues.

A one-way ANOVA revealed that the VEH (1424 \pm 73$)$, PRAZ $(1315 \pm 73)$, and ICI $(1545 \pm 82)$ groups did not differ in locomotor activity $\left(F_{(2,46)}=2.2, P=0.13\right)$, again suggesting that conditioned or residual effects of the drugs on locomotion do not explain the impairments in CPP seen during test 2 .

\section{Experiment 3B: Post-retrieval intra-BLA prazosin and $\mathrm{ICI} 118,551$ administration had no effect on CPP in the absence of retrieval}

The VEH, PRAZ, and ICI groups showed no difference in CPP in the absence of test 1 . Figure 8 shows the mean (+ SEM) time spent on the GRID floor during test 2 for the three groups. Separate twoway ANOVAs (post-test treatment $\times$ conditioning subgroup) were conducted between the PRAZ or ICI groups and the VEH group. Between the PRAZ and VEH groups, a two-way ANOVA revealed a significant main effect of conditioning subgroup $\left(F_{(1,14)}=43.7, P<0.001\right)$, indicating reliable preference across drug treatments for the cocaine-paired floor, but no interaction or main effect of prazosin $(F s<1)$. Between the ICI and VEH groups, a two-way ANOVA revealed a significant main effect of conditioning subgroup $\left(F_{(1,12)}=38.9, P<0.001\right)$, again indicating reliable preference across drug treatments for the cocaine-paired floor, but no interaction $(F<1)$ or main effect of ICI $118,551\left(F_{(1,12)}=1.4, P=0.26\right)$. Student's $t$-tests comparing time spent on the GRID floor for the GRID+ and GRIDsubgroups within each drug treatment confirmed that the VEH $\left(t_{(5)}=3.7, P<\right.$ $0.017)$, PRAZ $\left(t_{(7)}=4.3, P<0.005\right)$, and ICI $\left(t_{(7)}=5.2, P<0.005\right.$ [Bonferronicorrected $\alpha / 3=0.017]$ ) groups showed significant cocaine-induced CPP, suggesting that the effects seen in experiment $3 \mathrm{~A}$ were specific to exposure to the testing environment.

A one-way ANOVA revealed that the VEH $(1459 \pm 92)$, PRAZ $(1391 \pm 114)$, and ICI (1326 \pm 168$)$ groups did not differ in locomotor activity $(F<1)$.
Figure 9 shows the general placement range of injections into the BLA and a representative bilateral BLA cannulation.

\section{Experiment 4A: FOS-IR in the BLA following test for cocaine CPP}

FOS-IR in the BLA in response to differential exposure to floor cues during testing was higher in the choice condition than when these cues were presented separately. Behaviorally, rats in the choice floor condition of FOS expression analysis showed cocaine CPP (Fig. 10A), as confirmed by Student's $t$-test $\left(t_{(6)}=3.3, P<0.05\right)$.

Across the BLA, FOS-IR was higher in response to exposure to the choice $\mathrm{CS}+/ \mathrm{CS}$ - cues than that of either of the cues presented separately (Fig. 10B), an effect that was prominent in a more posterior region of the BLA (Fig. 10C). Figure 10D shows representative FOS-IR in the BLA for each of the three groups. For FOS analysis across the BLA (bregma -1.80 to -3.30 ) (Fig. 10B) and between ranges $(-1.80$ to $-2.30[\mathrm{~A}],-2.30$ to $-2.80[\mathrm{~B}]$, and -2.80 to $-3.30[\mathrm{C}]$ ) (Fig. 10C), a repeated-measures ANOVA (bregma range $\times$ test floor), with a Greenhouse-Geisser correction for a violation of sphericity, revealed a significant interaction $\left(F_{(2.7,28.5)}=4.4, P<0.05\right)$, as well as significant main effects of test floor $\left(F_{(2,21)}=4.5, P<0.05\right)$ and bregma range $\left(F_{(1.4,28.5)}=211.9, P<\right.$ 0.001). Follow-up ANOVAs between ranges $A$ and $B, B$ and $C$, and $\mathrm{A}$ and $\mathrm{C}$ all revealed significant interactions $\left(F_{(2,21)}>4.2, P \mathrm{~s}<\right.$ $0.05)$ and main effects of both test floor $\left(F \mathrm{~s}_{(1,21)}>4.0, P \mathrm{~s}<0.05\right)$ and bregma range $\left(F \mathrm{~s}_{(2,21)}>108.0, P \mathrm{~s}<0.05\right)$. One-way ANOVAs within each bregma range revealed a significant effect of floor in ranges $\mathrm{B}$ and $\mathrm{C}\left(F_{(2,21)}>4.5, P \mathrm{~s}<0.05\right)$, but not $\mathrm{A}\left(F_{(2,21)}=1.7, P=\right.$ $0.20)$. A Student's $t$-test examining range $B$ revealed a difference between the CS+/CS - and CS - groups $\left(t_{(14)}>2.8, P<0.05\right)$, a trend toward a difference in the CS+ and CS- groups $\left(t_{(14)}=1.9\right.$, $P=0.08)$, and no difference between the CS+/CS - and CS+ groups $\left(t_{(14)}=1.5, P=0.17\right)$. A Student's $t$-test examining range $C$ revealed differences between the CS+/CS - group and each of the other two groups $\left(\mathrm{CS}+\right.$ and $\left.\mathrm{CS}-; \mathrm{ts}_{(14)}>2.4, P \mathrm{~s}<0.05\right)$, but no difference between the CS+ and CS - group $\left(t_{(14)}=0.43, P=0.67\right)$. These results imply that FOS-IR is higher in response to exposure to the choice CS+/CS - cues than that of either of the cues presented

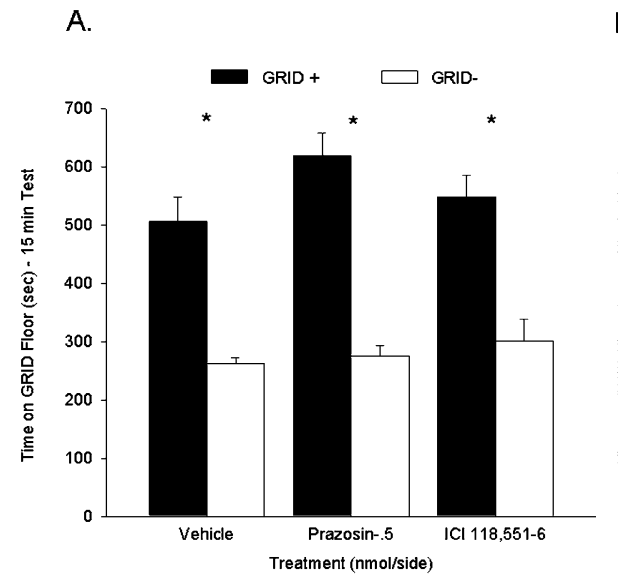

B.

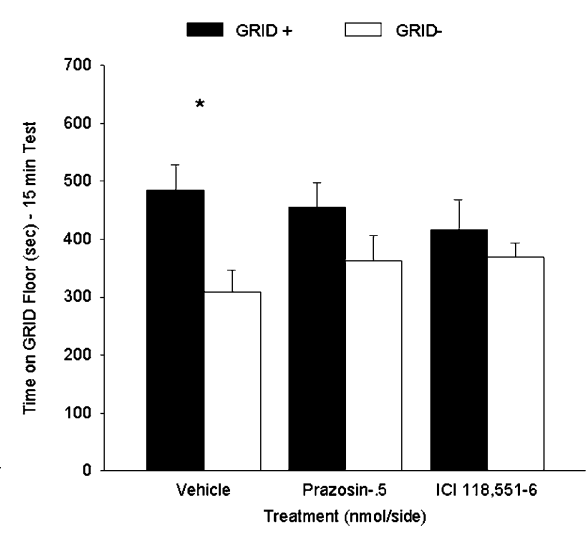

Figure 7. Post-retrieval intra-BLA administration of prazosin and $\mathrm{ICI} 118,551$ attenuated a subsequent cocaine-induced conditioned place preference (CPP). (A) Cocaine induced a CPP for the cocaine-paired floor during test 1 . Data represent mean (+ SEM) time spent on the GRID floor for the GRID+ and GRIDsubgroups during the 15-min drug-free test. All groups showed a significant preference for the cocainepaired floor. (B) Post-retrieval intra-BLA prazosin and ICI 118,551 following test 1 attenuated a cocaineinduced CPP during test 2. Data represent mean (+ SEM) time spent on the GRID floor for the GRID+ and GRID - subgroups during the first $15 \mathrm{~min}$ of a 25-min drug-free test. Rats treated with prazosin or $\mathrm{ICl} 118,551$ following test 1 showed no significant preference for the cocaine-paired floor during test 2 , while vehicle-treated rats continued to show a significant CPP. ${ }^{*} P<0.017$ (Bonferroni-corrected $\alpha / 3)$. 


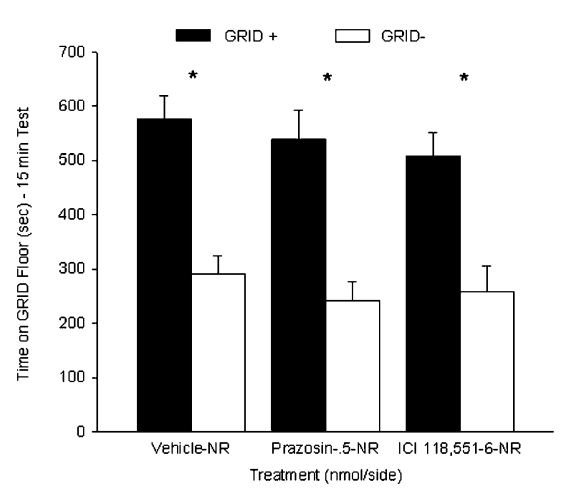

Figure 8. No effect of intra-BLA administration of prazosin or $\mathrm{ICI}$ 118,551 on a cocaine conditioned place preference (CPP) when administered in the absence of re-exposure. Data represent mean (+ SEM) time spent on GRID floor for the GRID+ and GRID- subgroups during the first $15 \mathrm{~min}$ of the 25-min drug-free test. Groups that received vehicle, prazosin, or $\mathrm{ICl} 118,551$ in the absence of test 1 (NR) all showed a significant cocaine CPP during test $2 .{ }^{*} P<0.017$ (Bonferroni-corrected $\alpha / 3)$. NR indicates no re-exposure.

separately. Because of the higher FOS response in range C, and the differences seen between floor conditions here, we decided to focus on this bregma range for experiment $4 \mathrm{~B}$.

\section{Experiment 4B: Systemic effects of prazosin and ICI 118,551 on a test for cocaine CPP and FOS-IR in the BLA} Rats in the choice floor conditions showed preference for the cocaine-paired floor that was not affected by prazosin or ICI 118,551 pretreatment. Figure $11 \mathrm{~A}$ shows the mean (+ SEM) time spent on the GRID floor during the test for all groups. A two-way ANOVA (drug pretreatment $\times$ conditioning subgroup) between the PRAZ-1 and VEH groups revealed significant effects of conditioning subgroup $\left(F_{(1,13)}=12.1, P<0.005\right)$ but no significant interaction or main effect of drug pretreatment $(F s<1)$. Between the ICI-8 and VEH groups, there was also a significant effect of conditioning subgroup $\left(F_{(1,13)}=18.5, P<0.005\right)$, but no significant interaction or main effect of drug pretreatment $(F \mathrm{~s}<1)$. Although it is clear that rats in groups VEH $\left(t_{(7)}=2.4, P=0.05\right)$, PRAZ-1 $\left(t_{(6)}=\right.$ $2.7, P<0.05)$, and ICI-8 $\left(t_{(6)}=5.4, P<0.005\right)$ showed a preference for the cocaine-paired floor, due to the small number of animals used for FOS analyses, all $P$-values did not reach our normal criterion for Bonferroni correction $(\alpha / 3=0.017)$.

FOS-IR was examined in BLA bregma range C $(-2.80$ to -3.30) (Fig. 11B). Animals with poor representation in bregma range $\mathrm{C}$ due to poor staining or tissue destruction were removed from analysis. Table 1 shows the number of animals per group used for FOS analyses in parentheses. To determine replication of the FOS-IR here to that seen in experiment 4A, an ANOVA was used to examine the effect of test floor $\left(F_{(2,20)}=4.5, P<0.05\right)$. Similar to the results in experiment $4 \mathrm{~A}$, $t$-tests revealed that groups CS + and CS - did not differ in FOS-IR $\left(t_{(13)}=1.4, P=\right.$ 0.18 ), while expression in the CS+/CS - group was significantly higher than that of the CS - group $\left(t_{(13)}=2.7, P<0.05\right)$ and trended toward significantly higher than that of the CS+ group $\left(t_{(14)}=1.8, P=0.10\right)$. A one-way ANOVA comparing FOS-IR in the VEH CS+/CS-, CS-/CS-, and NP groups revealed a significant group effect $\left(F_{(2,18)}=39.2, P<0.001\right)$. A follow-up $t$-test between the CS $-/ C S-$ and NP groups $\left(t_{(11)}=8.2, P<0.001\right)$ confirmed the procedural effects of the CPP paradigm on FOS-IR in the BLA. Furthermore, the CS+/CS - showed significantly higher FOS-IR than the CS $-/ C S-$ group $\left(t_{(13)}=2.8, P<0.05\right)$, suggesting that the novelty of the choice floor condition is not likely mediating the increase in the FOS response in the choice floor condition as seen in experiment $4 \mathrm{~A}$.
Between the VEH and PRAZ groups, a two-way ANOVA (drug pretreatment $\times$ test floor) revealed no significant interaction $\left(F_{(2,40)}=1.7, P=0.19\right)$ or main effect of drug $\left(F_{(1,40)}=1.2, P=\right.$ $0.29)$, or floor $\left(F_{(2,40)}=2.4, P<0.11\right)$. Thus, prazosin pretreatment had no effect on FOS-IR in the three floor conditions as a whole, though it appears in Figure 11B that there may be a trend toward attenuation of the response in the PRAZ CS+/CS - group, verified by $t$-test $\left(t_{(14)}=1.8, P=0.10\right)$. Between the VEH and ICI groups, a two-way ANOVA revealed a significant main effect of drug $\left(F_{(1,39)}=24.3, P<0.001\right)$, but no significant interaction $\left(F_{(2,39)}=\right.$ $2.1, P=0.14)$ or main effect of floor $\left(F_{(2,39)}=2.1, P=0.14\right)$. Follow up $t$-tests revealed that between the VEH and ICI groups, FOS-IR was significantly different in the $\mathrm{CS}+/ \mathrm{CS}-\left(t_{(13)}=3.9, P<0.005\right)$ and CS $+\left(t_{(13)}=3.0, P<0.01\right)$ conditions, but not the CS $-\left(t_{(13)}=\right.$ $1.5, P=0.16)$ condition. Thus, ICI 118,551 pretreatment attenuated the FOS response in both groups associated with the cocaine cue.

\section{Discussion}

These experiments are the first to demonstrate a role for $\alpha_{1}$ - and $\beta_{2}$-AR antagonists in retrieval-induced plasticity in cocaine CPP. Behavioral effects were observed with both systemic and intra-BLA administration, demonstrating the importance of the noradrenergic system in the BLA in post-retrieval memory mechanisms. Immunohistochemistry was also suggestive of a role of the BLA in post-retrieval memory processes and demonstrated that in CPP, stimulus configuration was an important mediator of cue-induced activation in the BLA.

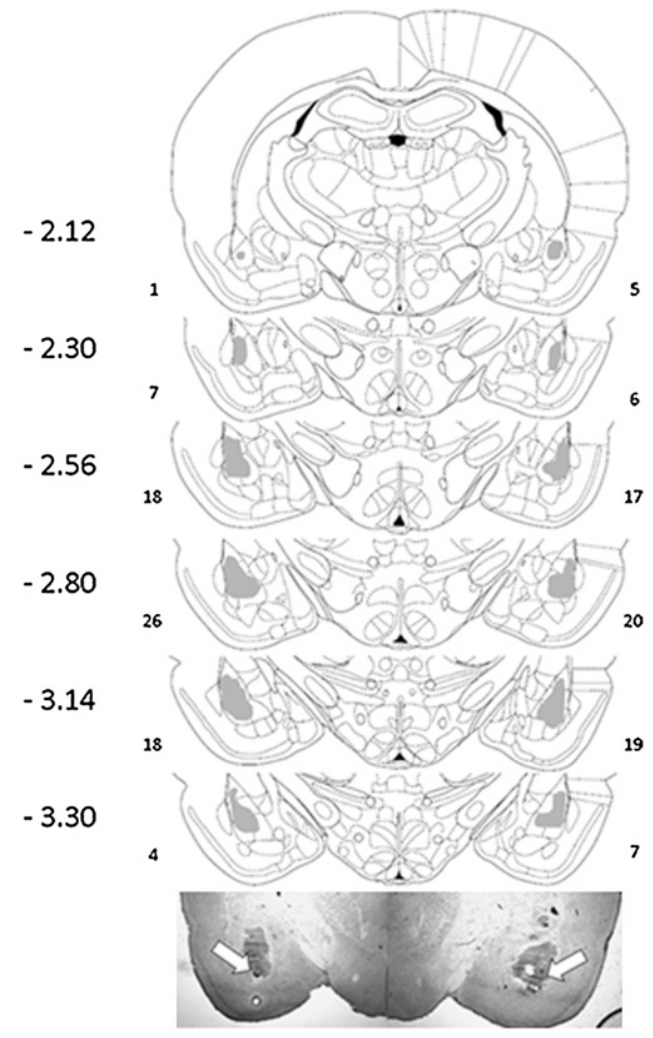

Figure 9. Areas in gray represent the cannula placements for intra-BLA studies. All cannulae were located within the gray areas. The far left represents $A / P$ coordinate with respect to bregma. Smaller numbers to the right and left of figure represent number of cannula placements within that bregma level. The lower-most figure is a representative slice from an intra-BLA bilaterally cannulated animal. White arrows indicate placement of dye injection. 
A.

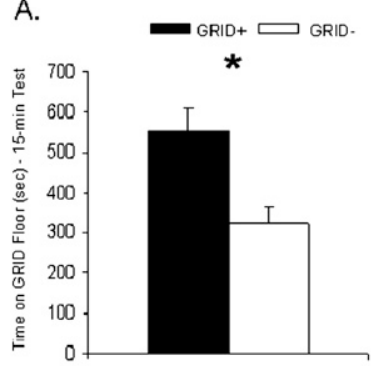

CS+/CS-
B.

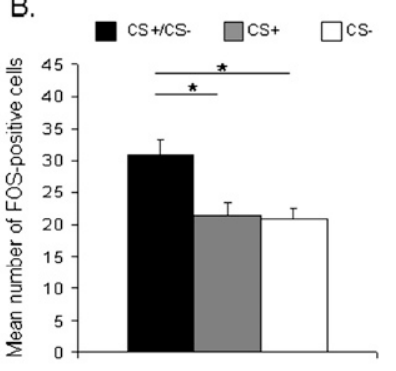

BLA-Total
C.

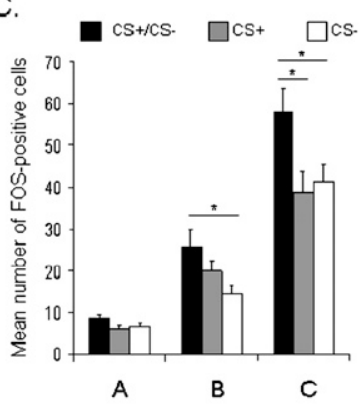

D.
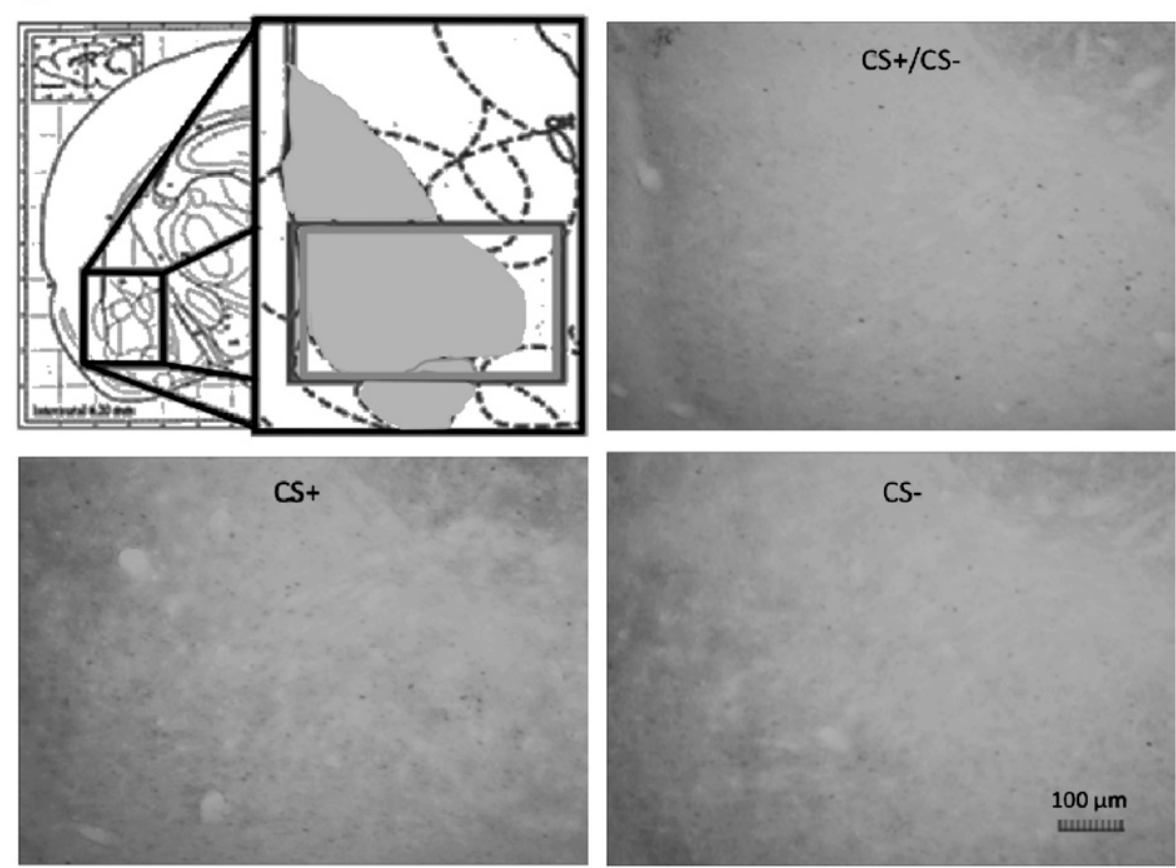

Figure 10. FOS-IR in the BLA after exposure to the $C S+/ C S$ - condition (choice floor) was higher than after exposure to either the CS+ or CS- conditions. (A) Animals in the CS+/CS - condition showed a conditioned place preference (CPP). Data represent mean (+ SEM) time spent on the GRID floor for the GRID+ and GRID - subgroups during the 15-min drug-free test. (B) Across the BLA $(-1.80$ to $-3.30)$, FOS-IR was significantly higher in the CS+/CS - condition than in the CS+ or CS - conditions. Data represent mean number of FOS-positive cells. (C) Across distinct bregma levels of the BLA, a similar pattern emerged in the most posterior region. Data represent mean number of FOS-positive cells. There were no differences in FOS-IR between the three floor conditions in bregma level A $(-1.80$ to -2.30$)$. In bregma level B $(-2.30$ to -2.80$)$, there was significantly higher FOS-IR in the CS+/CS - condition compared with the CS - condition, whereas the CS+ was not significantly different than either of the other two floor conditions. In bregma level C $(-2.80$ to -3.30$)$, FOS-IR was significantly higher in the $\mathrm{CS}+/ \mathrm{CS}$ - condition than in both the CS+ or CS - conditions, which showed similar levels of FOS response. $(D)$ Representative FOS-IR from each of the three floor configurations. Shaded in light gray in the upper left panel is the entire BLA as analyzed for immunohistochemistry. The dark gray box on the right side of the upper left panel indicates the area represented by the representative FOS-IR panels. $* P<0.05$.

We first examined the effects of post-retrieval administration of the $\beta_{1^{-}}$and $\beta_{2}$-AR antagonists betaxolol and ICI 118,551 . We found that ICI 118,551 attenuated a subsequent CPP, while betaxolol had no effect at either dose tested. Furthermore, ICI 118,551 administered to control rats in the absence of memory reactivation failed to affect a cocaine CPP. These results are consistent with previous work demonstrating post-retrieval impairment of a cocaine CPP using the nonspecific $\beta$-AR antagonist propranolol (Bernardi et al. 2006) and suggest that the effect of propranolol demonstrated in this previous study may be mediated by the $\beta_{2}$-AR. The results presented here are also

consistent with a number of other studies demonstrating impairment of possible reconsolidation processes via systemic $\beta$-AR blockade in drug-mediated learning paradigms, including morphine CPP (Robinson and Franklin 2007) and a cocaine cue-mediated acquisition of a new response paradigm (Milton et al. 2008), and several other nondrug learning tasks (Roullet and Sara 1998; Przybyslawski et al. 1999; Diergaarde et al. 2006; Abrari et al. 2008). Propranolol administered following retrieval of a fear memory in humans has recently been reported to completely abolish the expression of fear (Kindt et al. 2009), and thus our results extend findings in both human and animal studies by suggesting that the disruption of maladaptive memories can be achieved via more targeted AR antagonism.

The $\alpha_{1}$-AR antagonist prazosin, at the highest dose tested, also attenuated a cocaine-induced CPP when administered following memory retrieval. Furthermore, prazosin administered to rats in the absence of re-exposure to the drug environment failed to affect a subsequent preference. To date, no studies have demonstrated post-retrieval impairments using prazosin, though it has been demonstrated to play an important role in emotional memory processing (Ferry et al. 1999a,b).

One explanation for an attenuation of preference is an aversive conditioning effect of the post-test drug treatment. If ICI 118,551 or prazosin were aversive, the temporal proximity of the drug with the preferred, drug-paired floor during the initial test via immediate posttest administration might decrease preference on a subsequent test (Bormann and Cunningham 1997). We demonstrated here that administration of ICI 118,551 or prazosin following a single CS exposure, identical to the parameters in our post-retrieval studies, had no effect on a subsequent test. This suggests that ICI 118,551 and prazosin, at the doses we used, were not by themselves aversive. This does not preclude the possibility, however, that interactions of these drugs with the conditioned properties of cocaine present during testing may have different effects, and further studies are needed to elucidate these potential interactions.

Based on the large body of evidence indicating the importance of the BLA in mediating reconsolidation-like effects (Nader et al. 2000; Debiec and Ledoux 2004; Milekic et al. 2007), we examined the role of the BLA in mediating the post-retrieval impairments seen here with systemic adrenergic antagonists. Only one study to date has demonstrated AR blockade in the BLA as a useful tool for post-retrieval impairment. Debiec and LeDoux (2004) demonstrated that propranolol administered into the BLA following memory reactivation impaired an inhibitory avoidance 
A.

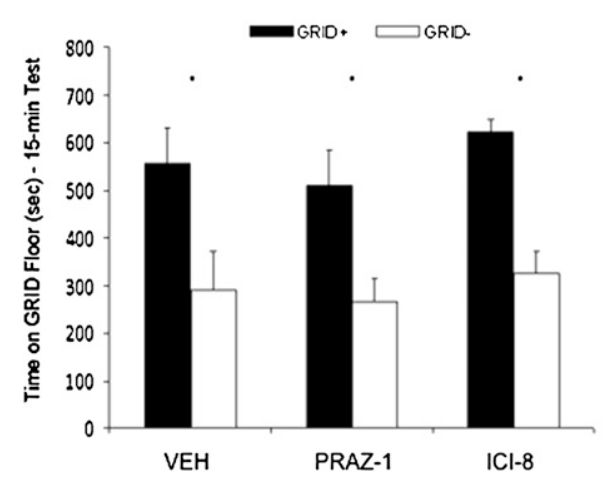

B.

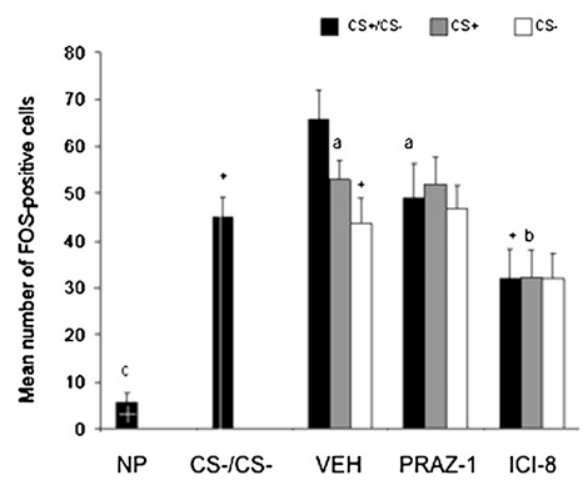

Figure 11. Pretreatment with $\mathrm{ICl} 118,551$ attenuated the $\mathrm{FOS}$ response in bregma level $\mathrm{C}$ of the BLA, while pretreatment with prazosin trended toward an attenuation of the FOS response. (A) Animals in the $\mathrm{CS}+/ \mathrm{CS}-$ conditions showed a conditioned place preference (CPP) that was unaffected by pretreatment. Data represent mean (+ SEM) time spent on the GRID floor for the GRID+ and GRIDsubgroups during the 15-min drug-free test. Animals pretreated with vehicle, prazosin, or ICl-118,551 all showed place preference (but see Results). (B) In bregma range C of the BLA $(-2.80$ to -3.30 ), FOSIR was significantly attenuated in both the $\mathrm{CS}+/ \mathrm{CS}$ - and $\mathrm{CS}+$ conditions in animals pretreated with

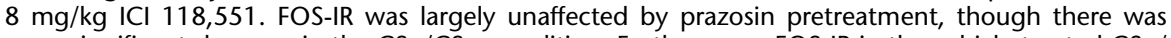
a nonsignificant decrease in the CS+/CS - condition. Furthermore, FOS-IR in the vehicle-treated CS+/ $\mathrm{CS}$ - was significantly higher than in animals that did not receive cocaine during conditioning but were tested in the presence of the choice floor (CS-/CS-). Data represent mean number of FOS-positive cells in each condition. ${ }^{*} P<0.05 ;{ }^{+} P<0.05$ (compared with VEH CS $+/ C S-$ ); ${ }^{a} P=0.10$ (compared with VEH CS+/CS-); ${ }^{b} P<0.05$ (compared with VEH CS+); ${ }^{c} P<0.05$ (compared with $C S-/ C S-$ ). VEH indicates vehicle; PRAZ-1, $1 \mathrm{mg} / \mathrm{kg}$ prazosin; ICl-8, $8 \mathrm{mg} / \mathrm{kg} \mathrm{ICI} \mathrm{118,551;} \mathrm{and} \mathrm{NP,} \mathrm{no} \mathrm{procedures.}$

memory in rats. Here, we have shown that noradrenergic blockade in the BLA translates to studies of drug conditioning. Our studies indicate, at least in the cocaine CPP paradigm examined here, that the post-retrieval effect of $\beta$-AR antagonism on subsequent cue responding can be achieved via intra-BLA $\beta_{2}$-AR antagonism with ICI 118,551, consistent with our systemic findings. We further demonstrated that the $\alpha_{1}$-AR antagonism with prazosin impaired a subsequent preference when administered into the BLA following memory retrieval, again consistent with our systemic findings.

A number of other findings have also suggested that the BLA mediates reconsolidation-like effects in drug learning paradigms. In the CPP paradigm, the protein synthesis inhibitors anisomycin and cycloheximide have been demonstrated to impair a subsequent morphine preference when administered into the BLA following a $\mathrm{CS}_{+} /$morphine conditioning trial in rats (Milekic et al. 2006). Furthermore, Wang et al. (2008) found that corticosterone, as well the glucocorticoid agonist RU28362, both impaired a subsequent morphine CPP in rats when microinjected into the BLA following an initial test. Glucocorticoids have been shown to interact with the adrenergic system in the BLA to modulate memory formation (Roozendaal et al. 2002). Interestingly, posttest administration of the protein synthesis inhibitor anisomycin into the BLA had no effect on a subsequent morphine CPP in rats (Yim et al. 2006). However, anisomycin administered into the BLA in rats has been shown to produce immediate and dramatic increases in norepinephrine there, as measured by microdialysis (Canal et al. 2007), which would have an effect opposite to that of adrenergic antagonism, and may be one reason post-retrieval anisomycin failed to impair morphine CPP.

Our FOS-IR studies were undertaken to distinguish between the FOS response in the BLA during a choice test versus the separate cues individually and to determine the effect of ICI 118,551 and prazosin on conditioned changes in FOS-IR to confirm the BLA as a mediator of post-retrieval effects. Previous studies have shown inconsistent results of conditioned cued FOS response in the BLA following cocaine conditioning. Franklin and
Druhan (2000) found no conditioned increase in the response of FOS-related antigens in the BLA in rats exposed to a context in which they had previously received multiple cocaine pairings. However, Miller and Marshall (2005) saw an increase in the FOS response in the BLA following a test for cocaine CPP. We found that FOS-IR in the BLA was higher after exposure to the CS+/CS- condition (choice) during testing than after exposure to either the CS+ or CS- floors. This effect was not due to the novel configuration of the chamber in the $\mathrm{CS}+/ \mathrm{CS}_{-}$ group, because a control group that received conditioning trials without cocaine and testing on the choice floor had a significantly lower FOS response in the BLA compared with that of cocaine-conditioned animals.

One possible explanation for the increased FOS response of the choice floor is an effect of behavioral contrast (Bevins 2005). Upon exposure to either the drug- or saline-paired floor, FOS-IR in the BLA is similar. However, upon exposure to the choice floor, the differential value of the cues is unmasked and the FOS response is increased in the BLA. Another possible explanation is that FOS-IR in the BLA upon expression of CPP reflects the learning of a CS+ approach response (Gremel and Cunningham 2008). As the choice floor can conceivably be thought of as a distinct, new environment, it is likely that this new experience requires processing of a variety of new information, including recognizing a new floor configuration, discriminating between the value of the two floors, and making a response based on this information. Thus it is possible that adrenergic antagonists disrupted memory formation based on this new information, resulting in an attenuated preference response upon subsequent testing, an idea consistent more with impaired consolidation rather than reconsolidation (Tronel et al. 2005). For example, a previous study has shown that disruption of protein synthesis in the nucleus accumbens core indeed impaired the learning of an appetitive instrumental response without affecting an already learned response when protein synthesis was disrupted following a retrieval trial (Hernandez et al. 2002). Because information about the motivational value of drug-paired cues is thought to be mediated in part by BLA projections to the nucleus accumbens (Everitt et al. 1999), it is conceivable that post-test noradrenergic blockade impaired the consolidation of the instrumental response induced during preference testing in the current studies.

Table 1. The number of animals in each group for experiment 3B

\begin{tabular}{llll}
\hline & \multicolumn{3}{c}{ Pre-Tx } \\
\cline { 2 - 4 } Floor & VEH & PRAZ-1 & ICI-8 \\
\hline CS+/CS- (choice) & $n=9(8)$ & $n=8(8)$ & $n=8(7)$ \\
CS+ & $n=8(8)$ & $n=8(7)$ & $n=8(7)$ \\
CS- & $n=8(7)$ & $n=8(8)$ & $n=8(8)$ \\
CS-/CS- (choice) & $n=9(7)$ & \\
& NP $n=6(6)$ \\
\hline
\end{tabular}

Across the top row are the three drug pretreatments, and down the far-left column are the different test floor configurations. In parentheses are the numbers of animals included in FOS expression analyses for each group. 
With respect to the drug pretreatments, ICI 118,551 attenuated the increased FOS response in the choice condition, as well as in the CS+ condition, while importantly having no effect on the behavioral expression or retrieval of CPP when administered prior to testing. This suggests a role for the BLA, and possibly FOS activation, in mediating post-retrieval processes via $\beta_{2}$-ARs. Prazosin, which also failed to affect preference when administered prior to testing, trended toward an attenuation of the FOS response, but only in the choice floor condition, suggesting a limited role for $\alpha_{1}$-adrenergic receptors in the BLA in post-retrieval processes. As noted above, these attenuations of the FOS response, because they were more apparent in the choice floor conditions, could be related to an impairment of consolidation of information learned during the CPP test. Regardless, our FOS results indicate that the BLA was undoubtedly involved in the conditioned effects of cocaine cues in our experiments. And though not definitive, the FOS results were suggestive of a post-retrieval effect of noradrenergic antagonism in the BLA. Given some of the differences in gene expression that occur after induction or retrieval of cue-associated learning (Lee et al. 2004), it will be important to further characterize the role of FOS in memory processes related to drug learning.

At a theoretical level, there are multiple mechanisms that could contribute to our results. As described above, it is possible that noradrenergic blockade disrupted the consolidation of the new instrumental conditioned response that develops during a choice test, thereby weakening the conditioned reinforcing value of the drug-paired floor. Most often, the loss of CPP following a post-retrieval manipulation has been attributed to effects on reconsolidation (e.g., Fricks-Gleason and Marshall 2008) and extinction (e.g., Groblewski et al. 2009; Malvaez et al. 2009). These interpretations are generally based on assumptions about the processes that underlie extinction or reconsolidation and on assumptions about how pharmacological manipulations act at a molecular level. For example, effects of drugs that are thought to impair memory are described in terms of reconsolidation, and effects of drugs that are thought to enhance memory are described in terms of enhanced extinction. But because extinction involves multiple processes, including formation of new memories (e.g., inhibitory CS-US or excitatory CS-no US) and depressions in previously established CS and US representations (e.g., Konorski 1967; Rescorla and Cunningham 1978; Robbins 1990), it is important to consider different ways that a drug might enhance extinction. The adrenergic manipulations used in the current studies may therefore modulate loss of CPP directly via facilitation of the formation of a new memory or indirectly via post-test decreases in arousal, attention, or affective value associated with the CS+ or US, consistent with the purported role of the noradrenergic system in these processes (for review, see Sara 2009).

A recent study using cocaine CPP found that the $\beta$-AR antagonist propranolol administered systemically to rats following a single test of cocaine CPP had no effect on either a subsequent test or, following further nonreinforced tests, cocaineprimed reinstatement (Fricks-Gleason and Marshall 2008). However, when propranolol was administered after each of a number of subsequent tests, preference decreased across trials relative to controls. Because no reinstatement of preference was seen during a cocaine-primed reinstatement test and because the absence of reinstatement has frequently been used as evidence against an enhanced extinction interpretation in studies demonstrating post-retrieval impairments, the investigators concluded that this finding represented an impairment of reconsolidation (FricksGleason and Marshall 2008). This is a very reasonable conclusion, but it also is important to consider that the absence of recovery is consistent with an enhancement of extinction, as any manipulation that enhances extinction should also weaken reinstatement and other recovery phenomena (Davis et al. 2006; Lattal and
Stafford 2008). Because repeated testing in the Fricks-Gleason and Marshall (2008) study resulted in several more trials during which propranolol-treated rats expressed no CPP compared with VEHtreated rats, this extra extinction training may have weakened reinstatement. A recent study demonstrated that propranolol induced a post-retrieval impairment of the fear response in human subjects but had no effect on the subjects' knowledge of the original fear contingency (Kindt et al. 2009), a finding consistent with extinction, in which a CS-US association is preserved, but the ability of the CS to evoke a response is weakened (Bouton 2004; Lattal et al. 2006).

Most studies that have tried to directly affect extinction processes have examined manipulations after one or more extinction sessions that result in a loss of behavior in VEH-treated animals. To date, there are no studies examining the effects of prazosin, ICI 118,551, or propranolol on extinction of cocaine CPP. Several studies have examined the effects of propranolol on extinction in other preparations, demonstrating that propranolol administered prior to an extinction session disrupts expression of conditioned fear and may impair the retention of extinction in some, but not all, situations (Gould 1998; Cain et al. 2004; Berlau and McGaugh 2006; Mueller et al. 2008; Rodriguez-Romaguera et al. 2009). Berlau and McGaugh (2006) found that intra-BLA administration of norepinephrine enhanced extinction of contextual fear and blocked the extinction-enhancing effect of the GABA antagonist bicuculline. These findings, as well as other studies of fear that show a specific role for $\beta$-ARs in selective reinstatement of fear (Morris et al. 2005), are consistent with a role of the BLA in modulating previously formed memories (e.g., Ferry et al. 1999a,b; Miranda et al. 2003). Studies like these in CPP paradigms will be helpful for understanding post-retrieval memory mechanisms involved in drug-associated learning.

In summary, we found that $\alpha_{1^{-}}$and $\beta_{2}$-AR antagonists can attenuate a subsequent cocaine CPP when administered after an initial test. This effect was seen both systemically and intra-BLA, confirming the BLA as one critical mediator of post-retrieval impairments. Because environmental stimuli that are associated with drugs of abuse are critical to the persistence of addiction in humans (Childress et al. 1988; Weiss 2005), targeting post-retrieval mechanisms via adrenergic blockade in the BLA represents a unique way to examine cue-induced drug-mediated behaviors in animals.

\section{Materials and Methods}

\section{Subjects}

Sprague-Dawley rats (Harlan, Indianapolis, Indiana) weighing 300-350 g (375-425 g for intracranial studies) at the beginning of experiments served as subjects. Subjects were housed two per cage in a temperature-controlled $\left(21^{\circ} \mathrm{C}\right)$ environment maintained on a 12-h light-dark cycle (lights on at 6 a.m.). Food and water were available ad libitum. All experiments were performed in accordance with the National Institutes of Health guidelines for the care and use of laboratory animals and the Institutional Animal Care and Use Committee of the Portland VA Medical Center. All behavioral testing was conducted during the light phase between $0700 \mathrm{~h}$ and $1600 \mathrm{~h}$.

\section{Apparatus}

CPP was assessed using an unbiased design (Cunningham et al. 2006) in four automated one-compartment place conditioning chambers (modified from San Diego Instruments). Each chamber consists of a clear acrylic test cage $(70 \mathrm{~cm} \times 23 \mathrm{~cm} \times 38.5 \mathrm{~cm})$ with removable floors composed of interchangeable halves (left/right) of two distinct floor types. A GRID floor consists of 2.3-mm stainless steel rods mounted $13 \mathrm{~mm}$ apart in an acrylic frame. A HOLE floor consists of perforated black acrylic with 13-mm round 
holes on 19-mm staggered centers (modified from the method of Bormann and Cunningham 1997). Pilot experiments have demonstrated that rats show approximately equal preference for the two floor types. Position in the chamber (left/right side) and general activity are assessed by computer software (San Diego Instruments) that records and analyzes beam interruptions from 16 infrared photocell emitter/detector pairs (eight evenly spaced pairs per left/right side) located along the long axis of the chamber, $1.5 \mathrm{~cm}$ above the chamber floor. Place conditioning chambers are housed in sound-attenuated, black acrylic enclosures (Flair Plastics) designed to eliminate noise from the external environment. Inside each chamber, a fan provides ventilation and a low level of masking noise.

\section{Drugs}

Cocaine $\mathrm{HCl}$ was obtained from Sigma and dissolved in physiological saline $(0.9 \% \mathrm{NaCl})$ for intraperitoneal (IP) injection $(1 \mathrm{~mL} / \mathrm{kg})$, and administered at a dose of $20 \mathrm{mg} / \mathrm{kg}$. For systemic (IP) administration studies, betaxolol $\mathrm{HCl}$ (Sigma) was administered at doses of 5 and $10 \mathrm{mg} / \mathrm{kg}$ ( $1 \mathrm{~mL} / \mathrm{kg}$ in physiological saline), ICI $118,551 \mathrm{HCl}$ (Sigma) was administered at a dose of $8 \mathrm{mg} / \mathrm{kg} \mathrm{(2} \mathrm{mL/}$ $\mathrm{kg}$ in sterile water), and prazosin $\mathrm{HCl}$ (Sigma) was administered at doses of 0.3 and $1 \mathrm{mg} / \mathrm{kg}$ ( $2 \mathrm{~mL} / \mathrm{kg}$ in sterile water). These doses were based on previous studies using these drugs in behavioral preparations in rats (Chojnacka-Wójcik et al. 1991; Rudoy and Van Bockstaele 2007; Freeman et al. 2008). For intra-BLA administration studies, ICI 118,551 and prazosin were dissolved in sterile saline and administered at doses of $6 \mathrm{nmol} / \mathrm{side}$ and $0.5 \mathrm{nmol} / \mathrm{side}$, respectively. These doses were loosely based on previous studies using these drugs for intracranial injections in behavioral preparations in rats (Ferry et al. 1999b; Leri et al. 2002; Qu et al. 2008). Intra-BLA infusions were administered at a volume of $0.5 \mu \mathrm{L}$ delivered over a 2-min period, and microinjectors were left in place for $1 \mathrm{~min}$ following infusions. VEH injections were administered at volumes equal to those described for individual drugs.

\section{Behavioral procedures (experiments 1, 3, and 4)}

Place conditioning involved the following phases performed on consecutive days: habituation, conditioning, and testing.

\section{Habituation (one session)}

During habituation, rats were injected with saline (IP, $1 \mathrm{~mL} / \mathrm{kg}$ ) and placed in the apparatus without floors for $25 \mathrm{~min}$ to reduce the stress associated with injections and exposure to the apparatus.

\section{Conditioning (eight sessions)}

Rats in each drug treatment group per experiment (outlined below) were randomly assigned to one of two conditioning subgroups (cocaine on GRID floor = GRID+; cocaine on HOLE floor $=$ GRID-) and exposed to a Pavlovian discrimination conditioning procedure (Cunningham et al. 2006). Thus, on alternate days over eight conditioning sessions (four cocaine sessions and four saline sessions), rats in the GRID+ subgroup received cocaine $(20 \mathrm{mg} / \mathrm{kg}$ IP) immediately prior to 25-min conditioning trials on the GRID floor and saline $(1 \mathrm{~mL} / \mathrm{kg} \mathrm{IP})$ immediately prior to 25 -min trials on the HOLE floor. Alternatively, rats in the GRID - subgroup received cocaine $(20 \mathrm{mg} / \mathrm{kg} \mathrm{IP})$ immediately prior to 25 -min conditioning trials on the HOLE floor and saline $(1 \mathrm{~mL} / \mathrm{kg} \mathrm{IP})$ immediately prior to 25-min trials on the GRID floor. The order of treatment exposure was counterbalanced within each GRID+ and GRID - subgroup, such that half of the rats in each subgroup received conditioning to cocaine during the first conditioning trial and half of the rats received saline during the first trial. During conditioning trials, left and right floor types were identical and rats had access to both sides of the apparatus (Cunningham et al. 2006).

\section{Testing (1 or 2 sessions)}

During test 1 , rats received a saline injection $(1 \mathrm{~mL} / \mathrm{kg}$ IP) immediately prior to placement into the apparatus with half GRID floor and half HOLE floor for a 15-min preference test designed to serve as a retrieval trial intended to reactivate the memory of the cocaine-cue association acquired during the conditioning phase. For the half GRID floor and half HOLE floor combination, the position of the floors (left vs. right) was counterbalanced within each GRID+ and GRID - subgroup, and magnitude of the place preference was determined by comparing the amount of time spent on the GRID floor between the GRID+ and GRID- conditioning subgroups (Cunningham et al. 2006). In experiments 1 and 3 , immediately following this test session, rats received drug treatment injections as outlined below and were returned to their home cages. Rats in no re-exposure groups (experiments 1C, 1E, and $3 \mathrm{~B}$ ) received similar drug treatments without re-exposure to the apparatus. Thus, these rats were administered drug treatments in their home cages. Twenty-four hours later, all rats received a saline injection ( $1 \mathrm{~mL} / \mathrm{kg}$ IP) immediately prior to placement into the apparatus with half GRID floor and half HOLE floor for a 25-min drug-free preference test (test 2) to assess the effect of post-retrieval drug treatments on a cocaine-induced CPP. Twenty five-minute tests were administered for test 2 to match conditioning trial duration, but data for test 2 was analyzed only for the first $15 \mathrm{~min}$ for direct comparison to test 1 retrieval trials. Again, preference was determined by comparing the amount of time spent on the GRID floor between the GRID+ and GRID- conditioning subgroups. Activity during test 2, as measured by the number of photobeam interruptions during the first $15 \mathrm{~min}$ of the 25-min test, was analyzed to determine if drug injections following test 1 had effects on locomotion that might affect a subsequent preference.

In experiments $4 \mathrm{~A}$ and $4 \mathrm{~B}$, animals were given a 15 -min preference test and euthanized for FOS immunohistochemistry. Furthermore, in experiment $4 \mathrm{~B}$, animals were pretreated with $\mathrm{VEH}$, prazosin, or ICI $118,55130 \mathrm{~min}$ prior to this 15 -min preference test as indicated below.

\section{Intracranial implantation, microinjection procedures, and histology (experiment 3 )}

\section{Intracranial implantation and microinjection procedures}

For intracranial implantation, rats were mounted onto a stereotaxic device (Stoelting) under deep isoflurane-induced anesthesia (4\% for induction and $1.5-2.5 \%$ maintenance) administered via inhalation. Rats were surgically implanted with bilateral 22-gauge guide cannulae (Plastics One) 4 or $5.5 \mathrm{~mm}$ above the BLA at the following coordinates: $\mathrm{A} / \mathrm{P}-2.9, \mathrm{M} / \mathrm{L} \pm 5.0, \mathrm{D} / \mathrm{V}-4.5$ or $\mathrm{A} / \mathrm{P}-2.9$, $\mathrm{M} / \mathrm{L} \pm 4.8, \mathrm{D} / \mathrm{V}-3.5$ (Paxinos and Watson 1998), with respect (in $\mathrm{mm}$ ) to Bregma, the midsagittal sinus and the surface of the level skull, respectively. The guide cannulae were secured to the skull with screws and dental acrylic. Cannulae were kept patent with 28-gauge dummy cannula (Plastics One). Bilateral intra-BLA microinjections were administered using a multi-syringe microinfusion pump (KD Scientific) and Hamilton syringes $(25 \mu \mathrm{L})$ with 28-gauge microinjectors (Plastics One) connected via preloaded PE 20 tubing. When inserted, microinjectors extended 4 or $5.5 \mathrm{~mm}$ beyond the chronically implanted guide shaft to reach the BLA.

After the behavioral testing was completed, rats were euthanized and injected with Coomassie blue dye $(0.5 \mu \mathrm{L})$ into their cannulae for placement verification. Brains were removed and flash frozen in methyl butane chilled on dry ice/isopropyl alcohol, then stored in $\mathrm{a}-80^{\circ} \mathrm{C}$ freezer. Brains were later sectioned on a cryostat, stained using cresyl violet and coverslipped, and placement in the BLA was verified. Only rats in which bilateral placement of the dye was correctly located within the BLA (including the basal, lateral, and accessory basal nuclei) were included in the statistical analyses of behavioral measures. Of 103 rats cannulated, 29 were removed from the study due to postsurgical illness or death, cannula removal, or incorrect placement.

\section{Immunohistochemistry procedures (experiment 4)}

\section{Tissue preparation}

Ninety minutes after the end of the 15 -min preference test in experiment 3 , rats were euthanized with sodium pentobarbital 
and transcardially perfused with phosphate-buffered saline (PBS), followed by $2 \%$ paraformaldehyde in PBS. Brains were then postfixed overnight in the same $2 \%$ paraformaldehyde solution, followed by cryoprotection in a $20 \%$, then $30 \%$, sucrose (in PBS) solution until saturated. Forty five-micrometer coronal slices were cut on a CM $3050 S$ cryostat (Leica Microsystems) and collected into PBS containing $0.1 \% \mathrm{NaN}_{3}$.

\section{Immunohistochemistry}

Staining for FOS was conducted using free-floating slices containing the BLA. Endogenous peroxidase activity was inhibited with $0.3 \%$ peroxide in PBS, and a $4.5 \%$ goat serum (Vector Laboratory) in a $0.3 \%$ Triton-X $100 / \mathrm{PBS}$ solution was used for blocking. Slices were incubated overnight in a 1:2500 dilution of a rabbit polyclonal antibody against FOS (sc-52; Santa Cruz Biotech) in PBS/ Triton-X with $0.1 \%$ bovine serum albumin (BSA). Slices were then incubated in a $0.3 \%$ Triton-X 100/PBS solution containing a goat anti-rabbit secondary antibody (Vector Laboratories), followed by detection of the immunoreaction using the Vectastain $A B C$ kit (Vector Laboratory) in a $0.3 \%$ Triton-X $100 / \mathrm{PBS}$ solution, and enzymatic development using the Metal Enhanced DAB kit (Thermo Scientific). Slices were subsequently mounted on gelatinized slides, dehydrated, and coverslipped.

\section{FOS quantification}

The number of FOS-containing cells was counted manually using a Leica DM4000 microscope (Bartels and Stout). The number of FOS-positive neurons from the left and right BLA (including the basal, lateral, and accessory basal nuclei) (see Fig. 10D) per section was totaled, and multiple sections per rat were averaged to produce a single data point for statistical analysis. For experiment 4A, 10 to 12 slices across the BLA (approximate bregma positions: -1.80 to $-3.30 \mathrm{~mm}$; two to six slices/bregma range: -1.80 to $-2.30[\mathrm{~A}],-2.30$ to $-2.80[\mathrm{~B}],-2.80$ to $-3.30[\mathrm{C}])$ were assessed. For experiment $4 \mathrm{~B}$, four to eight slices per bregma range $\mathrm{C}$ were assessed.

\section{Experiment 1: Systemic post-test administration of $\beta_{1^{-}}, \beta_{2^{-}}$, and $\alpha_{1^{-a d r e n e r g i c ~ a n t a g o n i s t s ~}}$}

\section{Experiment 1A: Post-retrieval betaxolol administration}

This experiment examined the effect of post-test administration of the selective $\beta_{1}$-adrenergic antagonist betaxolol on a subsequent test of cocaine CPP. Prior to behavioral procedures, rats were randomly assigned to one of three groups: VEH (BET-0; $n=24$; 12 per GRID+/GRID - conditioning subgroups), $5 \mathrm{mg} / \mathrm{kg}$ betaxolol (BET-5; $n=24 ; 12$ per GRID+/GRID - conditioning subgroups), and $10 \mathrm{mg} / \mathrm{kg}$ betaxolol (BET-10; $n=24 ; 12$ per GRID+/GRIDconditioning subgroups). All rats were subjected to the habituation, conditioning, and testing procedures described above. Rats in each group received the appropriate dose of betaxolol or VEH immediately following a drug-free test for place preference (test 1 ) and tested again for a CPP $24 \mathrm{~h}$ later (test 2).

\section{Experiment 1B: Post-retrieval ICI 118,551 administration}

This experiment examined the effect of post-test administration of the selective $\beta_{2}$-adrenergic antagonist, ICI 118,551 , on a subsequent test of cocaine CPP. Rats were randomly assigned to one of two groups: VEH (ICI-0; $n=24 ; 12$ per GRID+/GRID - conditioning subgroups) and $8 \mathrm{mg} / \mathrm{kg}$ ICI 118,551 (ICI-8; $n=24 ; 12$ per GRID+/GRID - conditioning subgroups). Rats were subjected to the habituation, conditioning, and testing procedures described above and received ICI 118,551 or VEH immediately following a drug-free test for place preference (test 1 ) and were tested again for a CPP $24 \mathrm{~h}$ later (test 2).

\section{Experiment $1 \mathrm{C}: \mathrm{ICI} 118,551$ administration in the absence of retrieval}

This experiment was a follow-up to experiment 1B. Rats were assigned to one of two groups: VEH-no re-exposure (ICI-0-NR; $n=$ 24; 12 per GRID+/GRID - conditioning subgroups) and $8 \mathrm{mg} / \mathrm{kg}$ ICI 118,551-no re-exposure (ICI-8-NR; $n=24 ; 12$ per GRID+/
GRID - conditioning subgroups). Rats were subjected to the habituation and conditioning procedures described above. However, rats in the ICI-0-NR and ICI-8-NR groups did not receive test 1 but received ICI 118,551 or VEH in their home cages, followed $24 \mathrm{~h}$ later by a test for CPP during test 2 . This omission of test 1 was intended to determine whether the effect of ICI 118,551 in experiment $1 \mathrm{~B}$ was specific to re-exposure to the cocaine environment.

\section{Experiment 1D: Post-retrieval prazosin administration}

This experiment examined the effect of post-test administration of the $\alpha_{1}$-adrenergic antagonist prazosin on a subsequent test of cocaine CPP. Rats were randomly assigned to one of three groups: VEH (PRAZ-0; $n=32 ; 16$ per GRID+/GRID - conditioning subgroups), $0.3 \mathrm{mg} / \mathrm{kg}$ prazosin (PRAZ-0.3; $n=32 ; 16$ per GRID+/ GRID - conditioning subgroups), and $1 \mathrm{mg} / \mathrm{kg}$ prazosin (PRAZ-1; $n=32 ; 16$ per GRID+/GRID - conditioning subgroups). All rats were subjected to the habituation, conditioning, and testing procedures described above. Rats in each group received the appropriate dose of prazosin or VEH immediately following a drug-free test for place preference (test 1) and tested again for a CPP $24 \mathrm{~h}$ later (test 2).

\section{Experiment 1: Prazosin administration in the absence of retrieval}

In a follow-up to experiment 1D, rats were again assigned to one of two groups: VEH-no re-exposure (PRAZ-0-NR; $n=24 ; 12$ per GRID+/GRID - conditioning subgroups) and $1 \mathrm{mg} / \mathrm{kg}$ prazosin-no re-exposure (PRAZ-1-NR; $n=24 ; 12$ per GRID+/GRID- conditioning subgroups). Rats were subjected to the habituation and conditioning procedures described above. However, rats in the PRAZ-0-NR and PRAZ-1-NR groups did not receive test 1 but received prazosin or VEH in their home cages, followed $24 \mathrm{~h}$ later by a test for CPP during test 2 . This omission of test 1 was intended to determine whether the effect of $1 \mathrm{mg} / \mathrm{kg}$ prazosin in experiment $1 \mathrm{D}$ was specific to re-exposure to the cocaine environment.

\section{Experiment 2: Test of the aversive effects of prazosin and ICI 118,55I}

It is possible that prazosin and ICI 118,551 have aversive properties that might result in a conditioned aversion that could mask preference upon subsequent testing (Bormann and Cunningham 1997). This experiment was conducted to determine if ICI 118,551 and prazosin affected preference during test 2 in experiments $1 \mathrm{~B}$ and $1 \mathrm{D}$ by the conditioning of an aversion to the cocaine-paired cue due to the temporal proximity of post-test injections with exposure to that cue, on which rats spend the majority of their time during preference testing. Such an effect would weaken preference by altering the value of the cocaine-paired cue. This experiment, unlike those above, was conducted over four consecutive days, involving one habituation session (as described above), two conditioning sessions (one GRID, one HOLE), and one test (as described above). In this case, conditioning trials consisted of a saline pre-injection and a 15-min CS exposure that was followed by prazosin, ICI 118,551, or VEH administration after exposure to one floor cue, and VEH administration after the other. This experiment was intended to emulate the post-15-min test drug injections used in experiments $1 \mathrm{~B}$ and $1 \mathrm{D}$ to determine if these injections were aversive. Thus, rats were randomly assigned to one of three groups: VEH ( $n=16$; eight per GRID-/GRID- conditioning subgroups), $1 \mathrm{mg} / \mathrm{kg}$ prazosin (PRAZ-1; $n=16$; eight per GRID+/GRID- conditioning subgroups), and $8 \mathrm{mg} / \mathrm{kg}$ ICI 118,551 (ICI-8; $n=16$; eight per GRID+/GRID - conditioning subgroups). Counterbalancing was as described above. Animals were tested for an aversion $24 \mathrm{hr}$ after the last of the two conditioning trials.

\section{Experiment 3A: Post-retrieval intra-BLA prazosin and ICI 118,551 administration}

This experiment examined the effect of post-test intra-BLA administration of the $\alpha_{1}$-adrenergic antagonist, prazosin, and the $\beta_{2}$-adrenergic antagonist, ICI 118,551, on a subsequent test of cocaine CPP. Rats were randomly assigned to one of three groups: VEH ( $n=16$; nine/seven per GRID+/GRID- conditioning 
subgroups), $0.5 \mathrm{nmol} /$ side prazosin (PRAZ; $n=17$; eight $/$ nine per GRID+/GRID - conditioning subgroups), and $6 \mathrm{nmol} /$ side ICI 118,551 (ICI; $n=16$; eight/eight per GRID+/GRID - conditioning subgroups). All rats were subjected to the habituation, conditioning, and testing procedures described above. Rats in each group received intra-BLA microinfusions of VEH, prazosin, or ICI 118,551 immediately following a drug-free test for place preference (test 1) and tested again for a CPP $24 \mathrm{~h}$ later (test 2).

\section{Experiment 3B: Post-retrieval intra-BLA prazosin and ICI 118,551 administration in the absence of retrieval}

In a follow-up to experiment $3 \mathrm{~A}$, rats were randomly assigned to one of three groups: VEH no re-exposure (VEH-NR; $n=9 ; 4 / 5$ per GRID+/GRID - conditioning subgroups), $0.5 \mathrm{nmol} /$ side prazosin (PRAZ-NR; $n=9 ; 5 / 4$ per GRID+/GRID- conditioning subgroups), and $6 \mathrm{nmol} /$ side ICI 118,551 (ICI-NR); $n=7 ; 3 / 4$ per GRID+ GRID - conditioning subgroups). Rats were subjected to the habituation and conditioning procedures described above. However, rats in the VEH-NR, PRAZ-NR, and ICI-NR groups did not receive test 1 , but received drug infusions in their home cages, followed $24 \mathrm{~h}$ later by a test for CPP during test 2 . This omission of test 1 was intended to determine whether the effect seen in experiment $3 \mathrm{~A}$ was specific to re-exposure to the cocaine environment.

\section{Experiment 4A: FOS-IR in the BLA following test for cocaine CPP}

The purpose of this experiment was to determine how different floor configurations during testing would affect the FOS response in the BLA. Previous studies have suggested somewhat inconsistent results regarding the response of FOS and FOS-related antigens following exposure to a cocaine-paired chamber versus a choice test for CPP (Franklin and Druhan 2000; Miller and Marshall 2005). Because a CPP test comprises a new configuration of cues for the animal, we sought to identify potential differences in the FOS response as a precursor to determining the role of adrenergic blockade in altering FOS-IR in experiment $4 \mathrm{~B}$. Rats were randomly assigned to one of three groups: choice floor (CS+/CS-; $n=8 ; 4$ per GRID+/GRID - conditioning subgroups), drug-paired floor (CS+; $n=8 ; 4$ per GRID+/GRID- conditioning subgroups), and saline-paired floor (CS-; $n=8 ; 4$ per GRID+/GRID- conditioning subgroups). Rats were subjected to the habituation and conditioning procedures described above, and given a 15-min drug-free exposure to the CS+/CS- floor configuration (as in a typical CPP test), the CS+ floor, or the CS- floor. Following testing, animals were processed for immunohistochemistry as described above.

\section{Experiment 4B: Systemic effects of prazosin and ICI 118,551 on a test for cocaine CPP and FOS-IR in the BLA}

This study examined whether the FOS response in the BLA was affected by pretreatment with the adrenergic manipulations that impaired preference following cued retrieval in experiments 1 and 3 , thereby possibly suggesting mediation of post-retrieval impairments by the cfos expression. Furthermore, based on the greater FOS response identified for the choice floor condition compared with the drug or saline floor condition in experiment $4 \mathrm{~A}$, we sought to determine whether the novelty of the choice floor could account for these differences. Table 1 outlines the groups used in this experiment and the number of animals per group. The FOS response in the BLA was again examined following exposure to different configurations of the cues present during conditioning, but animals were pretreated $30 \mathrm{~min}$ prior to testing with systemic VEH, $1 \mathrm{mg} / \mathrm{kg}$ prazosin, or $8 \mathrm{mg} / \mathrm{kg}$ ICI 118,551 , drug doses that were effective in producing impairment of CPP. It was hypothesized that pretreatment with prazosin or ICI 118,551 might impair the FOS response in the BLA induced by the expression of CPP without altering the behavior itself, thus confirming a postretrieval effect of these drugs. Rats were randomly assigned to one of nine groups, based on floor condition (identical to experiment 4A) and drug treatment (VEH, PRAZ-1, and ICI-8). These groups of rats were subjected to the habituation and conditioning procedures described above and, following drug pretreatment, were given a 15-min exposure to the appropriate floor configuration during testing. Two further groups were included here. A no procedures (NP) group consisted of rats that were not subjected to any of the conditioning or testing procedures of $\mathrm{CPP}$, included to determine changes in the FOS response in the BLA based solely on experimental procedures. The second group $(\mathrm{CS}-/ \mathrm{CS}-)$ received training and testing identical to the VEH CS+/CS - group, but received no cocaine during conditioning, instead receiving saline prior to conditioning trials with both floors. This group was included to control for the possibility that increases in the FOS response in the BLA were mediated by the novelty of the choice floor configuration. Following testing, animals were processed for immunohistochemistry as described above.

\section{Data analysis}

Statistical analyses were conducted with SPSS software. Place preference was analyzed using two-way ANOVAs (drug treatment dose $\times$ conditioning subgroup [GRID+/GRID-]). Student's $t$-test was used to make a priori comparisons of GRID+/GRID- subgroups where indicated (with a Bonferroni correction for multiple comparisons). Activity data during test 2 were analyzed using a one-way ANOVA (drug treatment).

For FOS analysis, one-way or two-way ANOVAs were used to analyze the number of FOS-positive cells per treatment group, as specified. Student's $t$-test was used for post-hoc analysis where indicated. Significance was set at $P<0.05$.

\section{Acknowledgments}

We thank Erika Spangler for help with the FOS studies and Chris Cunningham, Greg Mark, and Laura Kozell for helpful discussions. This research was supported by a grant from the Department of Veterans Affairs Merit Review program (07-1003) to S.P.B., a grant from the National Institute of Mental Health (R01 MH077111) to K.M.L., and grants from the National Institute on Drug Abuse to K.M.L. (R01 DA025922), A.E.R. (R03 DA025854), and R.E.B. (F31 DA022844).

\section{References}

Abrari K, Rashidy-Pour A, Semnanian S, Fathollahi Y. 2008. Administration of corticosterone after memory reactivation disrupts subsequent retrieval of a contextual conditioned fear memory: Dependence upon training intensity. Neurobiol Learn Mem 89: 178-184.

Berlau DJ, McGaugh JL. 2006. Enhancement of extinction memory consolidation: The role of the noradrenergic and GABAergic systems within the basolateral amygdala. Neurobiol Learn Mem 86: 123-132.

Bernardi RE, Lattal KM, Berger SP. 2006. Postretrieval propranolol disrupts a cocaine conditioned place preference. Neuroreport 17: 1443-1447.

Bevins RA. 2005. The reference-dose place conditioning procedure yields a graded dose-effect function. Int J Comp Psychol 18: 101-111.

Bormann NM, Cunningham CL. 1997. The effects of naloxone on expression and acquisition of ethanol place conditioning in rats. Pharmacol Biochem Behav 58: 975-982.

Bouton ME. 2004. Context and behavioral processes in extinction. Learn Mem 11: 485-494.

Cain CK, Blouin AM, Barad M. 2004. Adrenergic transmission facilitates extinction of conditional fear in mice. Learn Mem 11: 179-187.

Canal CE, Chang Q, Gold PE. 2007. Amnesia produced by altered release of neurotransmitters after intra-amygdala injections of a protein synthesis inhibitor. Proc Natl Acad Sci 104: 12500-12505.

Childress AR, McLellan AT, Ehrman R, O'Brien CP. 1988. Classically conditioned responses in opioid and cocaine dependence: A role in relapse? NIDA Res Monogr 84: 25-43.

Chojnacka-Wójcik E, Tatarczyńska E, Gołembiowska K, Przegaliński E. 1991. Involvement of 5-HT1A receptors in the antidepressant-like activity of gepirone in the forced swimming test in rats. Neuropharmacology 30: 711-717.

Cunningham CL, Gremel CM, Groblewski PA. 2006. Drug-induced conditioned place preference and aversion in mice. Nat Protoc 1: 16621670.

Davis M, Ressler K, Rothbaum BO, Richardson R. 2006. Effects of D-cycloserine on extinction: Translation from preclinical to clinical work. Biol Psychiatry 60: 369-375. 
Debiec J, LeDoux JE. 2004. Disruption of reconsolidation but not consolidation of auditory fear conditioning by noradrenergic blockade in the amygdala. Neuroscience 129: 267-272.

Diergaarde L, Schoffelmeer AN, De Vries TJ. 2006. $\beta$-Adrenoceptor mediated inhibition of long-term reward-related memory reconsolidation. Behav Brain Res 170: 333-336.

Diergaarde L, Schoffelmeer AN, De Vries TJ. 2008. Pharmacological manipulation of memory reconsolidation: Towards a novel treatment of pathogenic memories. Eur J Pharmacol 585: 453-457.

Everitt BJ, Parkinson JA, Olmstead MC, Arroyo M, Robledo P, Robbins TW. 1999. Associative processes in addiction and reward. The role of amygdala-ventral striatal subsystems. Ann N Y Acad Sci 877: 412438.

Ferry B, Roozendaal B, McGaugh JL. 1999a. Basolateral amygdala noradrenergic influences on memory storage are mediated by an interaction between $\beta$ - and $\alpha_{1}$-adrenoceptors. J Neurosci 19: 51195123.

Ferry B, Roozendaal B, McGaugh JL. 1999b. Involvement of $\alpha_{1}$-adrenoceptors in the basolateral amygdala in modulation of memory storage. Eur J Pharmacol 372: 9-16.

Franklin TR, Druhan JP. 2000. Involvement of the nucleus accumbens and medial prefrontal cortex in the expression of conditioned hyperactivity to a cocaine-associated environment in rats. Neuropsychopharmacology 23: 633-644.

Freeman KB, Verendeev A, Riley AL. 2008. Noradrenergic antagonism enhances the conditioned aversive effects of cocaine. Pharmacol Biochem Behav 88: 523-532.

Fricks-Gleason AN, Marshall JF. 2008. Post-retrieval $\beta$-adrenergic receptor blockade: Effects on extinction and reconsolidation of cocaine-cue memories. Learn Mem 15: 643-648.

Gawin FH. 1991. Cocaine addiction: Psychology and neurophysiology. Science 251: 1580-1586.

Gould TJ. 1998. $\beta$-Adrenergic involvement in acquisition vs. extinction of a classically conditioned eye blink response in rabbits. Brain Res 780: 174-177.

Gremel CM, Cunningham CL. 2008. Roles of the nucleus accumbens and amygdala in the acquisition and expression of ethanol-conditioned behavior in mice. J Neurosci 28: 1076-1084.

Groblewski PA, Lattal KM, Cunningham CL. 2009. Effects of D-cycloserine on extinction and reconditioning of ethanol-seeking behavior in mice. Alcohol Clin Exp Res 33: 772-782.

Hernandez PJ, Sadeghian K, Kelley AE. 2002. Early consolidation of instrumental learning requires protein synthesis in the nucleus accumbens. Nat Neurosci 5: 1327-1331.

Kindt M, Soeter M, Vervliet B. 2009. Beyond extinction: Erasing human fear responses and preventing the return of fear. Nat Neurosci 12: 256-258.

Konorski J. 1967. Integrative activity of the brain, an interdisciplinary approach. University of Chicago Press, Chicago, IL.

Lattal KM, Stafford JM. 2008. What does it take to demonstrate memory erasure? Theoretical comment on Norrholm et al. Behav Neurosci 122: 1186-1190.

Lattal KM, Radulovic J, Lukowiak K. 2006. Extinction: Does it or doesn't it? The requirement of altered gene activity and new protein synthesis. Biol Psychiatry 60: $344-351$.

Lee JL, Everitt BJ, Thomas KL. 2004. Independent cellular processes for hippocampal memory consolidation and reconsolidation. Science $\mathbf{3 0 4}$ 839-843.

Lee JL, Di Ciano P, Thomas KL, Everitt BJ. 2005. Disrupting reconsolidation of drug memories reduces cocaine-seeking behavior. Neuron 47: 795801.

Leri F, Flores J, Rodaros D, Stewart J. 2002. Blockade of stress-induced but not cocaine-induced reinstatement by infusion of noradrenergic antagonists into the bed nucleus of the stria terminalis or the central nucleus of the amygdala. J Neurol 22: 5713-5718.

Malvaez M, Sanchis-Segura C, Vo D, Lattal KM, Wood MA. 2009. Modulation of chromatin modification facilitates extinction of cocaineinduced conditioned place preference. Biol Psychiatry (in press). doi: 10.1016/j.biopsych.2009.07.032.

McGaugh JL. 2000. Memory-a century of consolidation. Science 287: 248251.

Milekic MH, Brown SD, Castellini C, Alberini CM. 2006. Persistent disruption of an established morphine conditioned place preference. J Neurosci 26: 3010-3020.

Milekic MH, Pollonini G, Alberini CM. 2007. Temporal requirement of $\mathrm{C} / \mathrm{EBP} \beta$ in the amygdala following reactivation but not acquisition of inhibitory avoidance. Learn Mem 14: 504-511.
Miller CA, Marshall JF. 2005. Altered Fos expression in neural pathways underlying cue-elicited drug seeking in the rat. Eur J Neurosci 21: 13851393.

Milton AL, Lee JL, Everitt BJ. 2008. Reconsolidation of appetitive memories for both natural and drug reinforcement is dependent on $\beta$-adrenergic receptors. Learn Mem 15: 88-92.

Miranda MI, LaLumiere RT, Buen TV, Bermudez-Rattoni F, McGaugh JL. 2003. Blockade of noradrenergic receptors in the basolateral amygdala impairs taste memory. Eur J Neurosci 18: 2605-2610.

Morris RW, Westbrook RF, Killcross AS. 2005. Reinstatement of extinguished fear by $\beta$-adrenergic arousal elicited by a conditioned context. Behav Neurosci 119: 1662-1671.

Mueller D, Porter JT, Quirk GJ. 2008. Noradrenergic signaling in infralimbic cortex increases cell excitability and strengthens memory for fear extinction. J Neurosci 28: 369-375.

Nader K. 2003. Memory traces unbound. Trends Neurosci 26: 65-72.

Nader K, Schafe GE, LeDoux JE. 2000. Fear memories require protein synthesis in the amygdala for reconsolidation after retrieval. Nature 406: $722-726$.

O'Brien CP, Childress AR, Ehrman R, Robbins S, McLellan AT. 1992. Conditioning mechanisms in drug dependence. Clin Neuropharmacol 15: $66 \mathrm{~A}-67 \mathrm{~A}$.

Paxinos G, Watson C. 1998. The rat brain in stereotaxic coordinates. Academic Press, San Diego, CA.

Przybyslawski J, Roullet P, Sara SJ. 1999. Attenuation of emotional and nonemotional memories after their reactivation: Role of $\beta$ adrenergic receptors. J Neurosci 19: 6623-6628.

Qu LL, Guo NN, Li BM. 2008. $\beta 1$ - and $\beta 2$-adrenoceptors in basolateral nucleus of amygdala and their roles in consolidation of fear memory in rats. Hippocampus 18: 1131-1139.

Rescorla RA, Cunningham CL. 1978. Within-compound flavor associations. I Exp Psychol Anim Behav Process 4: 267-275.

Robbins SJ. 1990. Mechanisms underlying spontaneous recovery in autoshaping. J Exp Psychol Anim Behav Process 16: 235-249.

Robinson MJ, Franklin KB. 2007. Central but not peripheral $\beta$-adrenergic antagonism blocks reconsolidation for a morphine place preference. Behav Brain Res 182: 129-134.

Rodriguez-Romaguera J, Sotres-Bayon F, Mueller D, Quirk GJ. 2009. Systemic propranolol acts centrally to reduce conditioned fear in rats without impairing extinction. Biol Psychiatry 65: 887-892.

Roozendaal B, Quirarte GL, McGaugh JL. 2002. Glucocorticoids interact with the basolateral amygdala $\beta$-adrenoceptor-cAMP/cAMP/PKA system in influencing memory consolidation. Eur J Neurosci 15: 553-560.

Roullet P, Sara S. 1998. Consolidation of memory after its reactivation: Involvement of $\beta$ noradrenergic receptors in the late phase. Neural Plast 6: $63-68$.

Rudoy CA, Van Bockstaele EJ. 2007. Betaxolol, a selective $\beta_{1}$-adrenergic receptor antagonist, diminishes anxiety-like behavior during early withdrawal from chronic cocaine administration in rats. Prog Neuropsychopharmacol Biol Psychiatry 31: 1119-1129.

Sara SJ. 2000. Retrieval and reconsolidation: Toward a neurobiology of remembering. Learn Mem 7: 73-84.

Sara SJ. 2009. The locus coeruleus and noradrenergic modulation of cognition. Nat Rev Neurosci 10: 211-223.

See RE. 2005. Neural substrates of cocaine-cue associations that trigger relapse. Eur J Pharmacol 526: 140-146.

Taylor JR, Olausson P, Quinn JJ, Torregrossa MM. 2009. Targeting extinction and reconsolidation mechanisms to combat the impact of drug cues on addiction. Neuropharmacology 56: (Suppl. 1) 186-195.

Tronel S, Milekic MH, Alberini CM. 2005. Linking new information to a reactivated memory requires consolidation and not reconsolidation mechanisms. PLoS Biol 3: e293. doi: 10.1371/journal.pbio.0030293.

Tronson NC, Taylor JR. 2007. Molecular mechanisms of memory reconsolidation. Nat Rev Neurosci 8: 262-275.

Wang XY, Zhao M, Ghitza UE, Li YQ, Lu L. 2008. Stress impairs reconsolidation of drug memory via glucocorticoid receptors in the basolateral amygdala. J Neurosci 28: 5602-5610.

Weiss F. 2005. Neurobiology of craving, conditioned reward and relapse. Curr Opin Pharmacol 5: 9-19.

Yim AJ, Moraes CR, Ferreira TL, Oliveira MG. 2006. Protein synthesis inhibition in the basolateral amygdala following retrieval does not impair expression of morphine-associated conditioned place preference. Behav Brain Res 171: 162-169.

Received September 26, 2009; accepted in revised form October 8, 2009. 


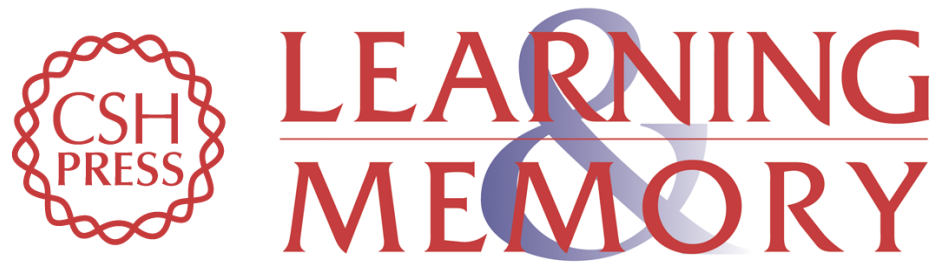

\section{Post-retrieval disruption of a cocaine conditioned place preference by systemic and intrabasolateral amygdala $\beta_{2}$ - and $\alpha_{1}$-adrenergic antagonists}

Rick E. Bernardi, Andrey E. Ryabinin, S. Paul Berger, et al.

Learn. Mem. 2009, 16:

Access the most recent version at doi:10.1101/lm.1648509

References This article cites 62 articles, 16 of which can be accessed free at: http://learnmem.cshlp.org/content/16/12/777.full.html\#ref-list-1

License

Email Alerting

Receive free email alerts when new articles cite this article - sign up in the box at the Service top right corner of the article or click here. 